University of San Diego

Digital USD

1988

\title{
The Impact of the Father/Daughter Relationship on Women in Educational Administrative Leadership Positions
}

Marilyn Ann Skordas EdD

University of San Diego

Follow this and additional works at: https://digital.sandiego.edu/dissertations

Part of the Leadership Studies Commons

\section{Digital USD Citation}

Skordas, Marilyn Ann EdD, "The Impact of the Father/Daughter Relationship on Women in Educational Administrative Leadership Positions" (1988). Dissertations. 518.

https://digital.sandiego.edu/dissertations/518

This Dissertation: Open Access is brought to you for free and open access by the Theses and Dissertations at Digital USD. It has been accepted for inclusion in Dissertations by an authorized administrator of Digital USD. For more information, please contact digital@sandiego.edu. 


\section{THE IMPACT OF THE FATHER/DAUGHTER RELATIONSHIP}

ON WOMEN IN EDUCATIONAL ADMINISTRATIVE

\section{LEADERSHIP POSITIONS}

by

Marilyn Ann Skordas

A dissertation submitted in partial fulfillment of the requirements for the degree of

Doctor of Education

University of San Diego

1988

\section{Dissertation Committee}

Susan M. Zgliczynski, Ph.D., Director William P. Foster, Ed.D. Johanna S. Hunsaker, Ph.D. 
(C) Copyright 1988

Marilyn Ann Skordas

All Rights Reserved 
The Impact of the Father/Daughter Relationship on Women in Educational Leadership Positions

Skordas, Marilyn Ann, Ed.D. University of San Diego, 1988 Director: Susan M. Zgliczynski, Ph.D.

Research studies by Cartwright (1970), Helson (1971), and Hennig (1976) have indicated and demonstated that a father's influence is critical to the development of skills in women who successfully obtained a position in business, medicine, and math, male dominated occupations. The public school teaching profession in the United States is an occupation dominated by women; however, the administrative positions such as principal, assistant superintendent, and superintendent positions of school districts are male dominated.

This case study investigated the father/daughter relationship experienced during middle childhood, early and later adolescence, and early adulthood of ten women who are currently in positions of principal and/or higher in San Diego County public school system in San Diego, California. Subjects were obtained from the membership of the San Diego Council of Administrative Women in Education.

Data collected and analyzed from the Dissertation Interview Information Sheet and responses to the Interview Questionnaire responded to two research questions:

1. What are the commonalities and/or differences of paternal parenting styles between the ten selected subjects? 
2. What are the identifying behavior patterns/interactions the father demonstrated that assisted his daughter with and through the developmental tasks and psychosocial crisis during her middle childhood, early and later adolescence, and early adulthood years that encouraged and motivated the woman to become a teacher and later an administrator in the field of education?

Findings indicated the fathers of the ten selected subjects were encouraging, supportive, and accepting of their daughters' decisions and life goals. Subjects were confident and academically successful students. They were later to become successful goal and career oriented educational leaders. Eight of the ten women were first born.

Recommendations were made to expand research studies regarding (1) the impact and influence of the father in the family unit, (2) the father/daughter relationship, (3) the new father and his relationship with his infant daughter, and (4) the coordination and collaborative efforts of all disciplines to share their findings about fathering with social agencies and educational institutions. 
To the Past

My Sister

My Brother-In-Law

My Niece
In Memory of

Shelby Allen Mark McKeen June 29, 1943 - July 17, 1983

Laurence Henry McKeen March 13, 1943 - Juty 18, 1983

Kimberly Ann McKeen March 30, 1970 - July 24, 1983

Tragically killed by a drunk driver in Gallup, New Mexico, July 1983.

To the Future

My Son

My Daughter

My Niece

My Niece

My Nephew

$$
\begin{gathered}
\text { Jeffrey Will iam Skordas } \\
\text { February 14, } 1965
\end{gathered}
$$

Cynthia Margaret Skordas

February 8, 1969

Molly Lynn McKeen

May 18, 1974

Amy Tumbridge Young

February 11, 1970

Timothy Howard Young

February 23, 1974 


\section{ACKNOWLEDGEMENTS}

My thoughts now turn to those who provided me with love, guidance, advice, and emotional support during my education at USD.

- to my children, Jeff and Cindy, who I am so very proud of and love very much -

- to my dear and very special parents, Nada and Clyde Hanks, who have been there for me and with me for many years -

- to my dear and very special friends, Pat Marshall, Jeanne Ford, Susan Sargent, and so many others who shared so much with me -

- to my committee members, Dr. Susan Zgliczynski, Dr. William Foster, and $\mathrm{Dr}$. Johanna Hunsaker, whose time and support assisted me to make this dissertation possible -

- to my advisor, Dr. Joseph Rost, whose guidance, patience, and demand for perfection assisted me to reach my dream - that of becoming a principal. 
Table of Contents

Page

Dedication $\quad$ ii

Acknowledgements iij

List of Tables vii

List of Appendices viii

Chapter

I. Introduction 1

Statement of the Problem 4

Research Questions 5

The Importance of the Problem 6

Definition of Terms 9

$\begin{array}{ll}\text { Assumptions } & 10\end{array}$

Limitations 11

11. Review of the Literature 12

Historical Perspective of Fathering 12

The Father's Influence on His Daughter:

An Overview 15

Life Stages $\quad 17$ 
Middle Childhood $\quad 17$

Adolescence $\quad 25$

Early Adolescence $\quad 27$

Later Âdolescence $\quad 31$

Early Adul thood $\quad 40$

Summary 46

III. Research Design 47

Case Study Method 47

Population 48

Data Collection Procedures 53

The Interview

The Interview Guide $\quad 56$

Data Analysis Procedures 61

Summary 63

IV. Findings 65

Dissertation Information Interview Sheet 65

Interview Questionnaire Findings $\quad 79$

Middle Childhood $\quad 80$

Early Adolescence $\quad 85$

Later Adolescense $\quad 94$

Early Adulthood 101

$\begin{array}{ll}\text { Summary } & 108\end{array}$ 
V. Summary Findings 109

Summary of Life Stages $\quad 110$

$\begin{array}{ll}\text { Middle Childhood } & 110\end{array}$

$\begin{array}{ll}\text { Early Adolescence } & 112\end{array}$

Later Adolescence $\quad 114$

$\begin{array}{ll}\text { Early Adul thood } & 116\end{array}$

$\begin{array}{ll}\text { Composite } & 118\end{array}$

Information for New Fathers $\quad 124$

$\begin{array}{ll}\text { Summary } & 126\end{array}$

VI. Conclusions and Recommendations . . 128

$\begin{array}{ll}\text { Conclusions } & 128\end{array}$

Dissertation Information Interview Sheet 128

Interview Questions 131

Middle Childhood 131

Early Adolescence $\quad 132$

Later Adolescence $\quad 134$

Early Adulthood $\quad 137$

Recommendations for Future Research 141

$\begin{array}{ll}\text { Summary } & 144\end{array}$

$\begin{array}{ll}\text { References } & 148\end{array}$

$\begin{array}{ll}\text { Appendices } & 158\end{array}$

vi 


\section{List of Tables}

Table

1. Location of Subjects During Middle Childhood, Adolescence and Early Adulthood Years

2. Subjects' Parents' Current Ages, Occupations, and Education

3. Birth Order of Subjects, Their Siblings, Current Ages, Occupations, Education

4. Descriptive Adjectives Selected by Subjects to Describe Fathers

5. Descriptive Adjectives Selected by Subjects to Describe Mothers 


\section{List of Appendices}

\section{Appendix}

A. San Diego Council of Administrative Women

in Education Newsletter - Advance, April 1986.

B. Letter of Appreciation to Pre-selected Candidates.

C. University of San Diego Consent Form

D. Dissertation Interview Information Sheet

E. Interview Guide 
For a woman to understand how her history with her father influences her capacity for a fulfilling career and emotional intimacy she must comprehend fully all their years together and the effect they have had (Appleton, 1981).

For a woman to be original requires strength, confidence in her own thinking power, a willingness to stand up to questioning and even attack, and the courage to query the conventional wisdorn and try something new (Appleton, 1981). 


\section{CHAPTER I}

\section{Introduction}

There has been a major shift in the family life in western societies since the onset of the Industrial Revolution. Stricter division of labor practices and roles within the life of the family established new patterns of behavior and role expectations for each member of the family unit.

The world of industry demanded that the new factory worker not only work longer hours, but work away from the familiar setting of his home and family. This change meant that the mother in the family assumed not only the responsibility of caretaking for the children, but also childrearing. The father, on the other hand, changed from an "influential agent of socialization to economic provider". (Lamb, 1981, p. 2). No longer was the father available to facilitate family activities and provide training for the development of specialized skills in his children. The depth of the father's influence in childrearing practices diminished considerably (Green, 1976; Lamb, 1981; Rivers, 1979).

Long after the labor market changed and there was no further need for fathers to work long hours away from home the maternal and paternal behavior patterns and role expectations of labor activities within the family context did not change. The psychologists, sociologists, and 
anthropologists who had grown up in and were socialized by a culture where the majority of parenting practices had been assumed by the mother "while the father pursued advancement and money outside the home" (Lamb, 1981, p. 4) focused their research studies, cultural and clinical observations on the maternal influence on childrearing practices. "In their concentration on mother and child, they were not only assuming the existence of a special relationship, but also assuming the absence of any comparable relationship between father and child" (Rivers, 1979, p. 16).

The behavioral scientists enhanced the concept of the diminished or devalued paternal influence within the family unit (Green, 1976; Hamilton, 1971; Lamb, 1981; Stevens \& Mathews, 1978; Stein, 1977) further perpetuating the mystification of motherhood (Rivers, 1979). Appleton (1981) states that the father has been a "wrongfully and excessively" (p. 28) ignored person, and hence, by implication, culturally and socially an unimportant person in the socialization of the child (Keller, 1980). According to Keller (1980) this represents something of a paradox; men and masculine roles associated with males are valued in our society, while the paternal roles are devalued. World War II had a major impact upon the family. Fathers began to be noticed, "but mainly by virtue of their absence" (Barnett \& Bauch, 1978, p. 52). Early findings of the father's absence from the home as a result of World War II indicate that the absence posed more problems for the sons rather than for daughters (Biller, 1971, 1974).

The major concern about the father's absence as far as girls 
were concerned was its effect on her sex-role development and her ability to form a heterosexual relationship in later life. It is important for a boy to develop skills; what matters for a girl is her ability to marry successfully (Rivers, 1979, p. 22).

The researchers did not investigate the development of girls' skills as a result of the father's absence. Barnett (1978) states that the sparseness of research studies for daughters is attributed to the fact that in "58 of 60 major studies the effects on daughters were not the primary focus" (p. 52). It is obvious that researchers at this time assumed that the major impact of an absent father would be on his son, not his daughter, a clear indication of what society's values were at that time in history.

It was not until the late 1960 's that the father started once again to become an influential agent in the home and to have an impact on the socialization process of children in the family unit (Lamb, 1981; Rivers, 1979). This change was in response to a number of sociological, economic, and political factors. These factors, discussed later in this text, have sociologists, psychologists, and educators reviewing and evaluating the impact of the father's role in the family unit as it is today.

Behavioral scientists such as Kotelchuck and Lamb questioned the amount of hard data available that supports the notion that children relate uniquely only to their mothers (Rivers, 1979). Their research as well as that of others "emphasized the need to examine the environmental 
influences and the interpersonal relationships that shape personality and behavior, and was thus able to suggest a new perspective on the father/daughter relationship" (Fields, 1983, p. 20).

\section{Statement of the Problem}

It has been noted in the studies of Cartwright (1970), Hennig (1976), Helson (1971) that the major element in the lives of successful women in the fields of medicine, business, and math was the influence and impact the supportive father had upon their achievements. The socialization process of those women during their middle childhood, adolescence and early adulthood was crucial to their entering male dominated occupations. These successful women portrayed their fathers as the most influential force in their development of careers.

The public school teaching profession in the United States is an occupation dominated by women; however, the administrative positions such as principals for elementary and secondary levels, assistant superintendent and superintendent positions of school districts are male dominated (Antonucci, 1980; Fishe1 and Pottker, 1979; Metzger, 1985; Shakeshaft, 1987; Tibbetts, 1979; Truett, 1979; Woo, 1985). A wealth of research studies investigated the various reasons why there is a lack of representation of women in administration leadership positions; however, no research exists with regard to the impact the father/daughter relationship had on women who now hold administrative leadership positions in education. 
This research study explored the father/daughter relationship of ten women as they experienced that relationship during their middle childhood, adolescence, and early adulthood years. The purpose of this study was to investigate, using a case study, those aspects of the father/daughter relationship that assisted, motivated, and inspired the woman (daughter) to obtain a teaching position and later an administrative/leadership position in the field of education.

\section{Research Questions}

This study investigated the father/daughter relationship experienced during middle childhood, early and later adolescence, and early adulthood of ten women who are currently in positions of principal and/or higher in the San Diego County public school system in San Diego, California. Questions to be addressed:

1. What are the commonalities and/or differences of paternal parenting styles between the ten selected subjects?

2. What are the identifying behavior patterns/interactions the father demonstrated that assisted his daughter with and through the developmental tasks and psychosocial crisis during her middle childhood, early and later adolescence, and early adulthood years that encouraged and motivated the woman to become a teacher and later an administrative leader in the field of education? 
The Importance of the Problem

Dr. Michael Lamb, a prominent researcher in the field of father/daughter relationships stated that "fathers have long been the forgotten parent, and daughters the forgotten offspring" (p. 2). Feldman (1983) stated further that:

research on the antecedents of fathering is particularly rare since it has been mainly within the past decade that child psychologists "discovered" the father and acknowledged his formative role in the socialization of children. It has been established that a father's involvement with children is neither incidental to him, infrequent, nor without significant psychological consequences for the child (p. 1629). According to Green (1976), Appleton (1981), Fields (1983), and Lamb (1981), the American society of the 1980's has found a renewed interest and reappraisal of the impact of this relationship on the daughter due to two specific reasons: (a) today more than two thirds of women between the ages of 25 and 44 are employed, creating a profound effect on the American family as well as on the workplace where these women must deal primarily with a male workforce (U.S. News and World Report, 1984) and (b) the increase in the divorce rate in the United States has left more daughters without fathers in the home (Green, 1976). It is estimated that a third of all children will spend part of their growing-up years in a single-parent household, and more than half will have working mothers (U.S. News and World Report, 1984). Since more than half of 
young women in America expect to work most of their adult lives, the value and importance of their work will steadily increase as will the need for training necessary to compete in the specialized job market (Woolfolk, 1982).

The role of women in American society (which is primarily an achievement-oriented system) has over the years been little understood and much ignored by psychologists. A peculiar paradox arises in the society because we have an educational system that ostensibly encourages and prepares men and women identically for careers that social and, even more importantly, internal psychological pressures really limit to men. This paradox is reflected by the feelings of the women who somehow overcome these pressures and pursue a particular career (Horner, 1977, p. 32).

Research studies done by Cartwright (1970), Hennig (1976), and Helson (1971) have indicated and demonstrated that a father's influence is critical to the development of skills in women who successfully obtained a position in business, medicine, and math. The importance of the father/daughter relationship is crucial to the daughter's understanding and perception of her own achievement, competence, and ambition, in the fulfillment of a career and in emotional intimacy with men (Fields, 1983; Hammer, 1982; Appleton, 1981). The major task set before us according to Lamb (1981), is to determine how and how much that relationship impacts a woman's 1ife.

The recent literature about educational administrative 
opportunities for women reflects the problems of (a) socialization, (b) stereotyping, (c) limited access to education and employment opportunities, (d) lack of affirmative action by educational institutions and (e) the fact of female role models for women setting their career goals (Adkison, 1981; Andre, 1979; Antonucci, 1980; Cummings, 1979; Gordon, 1979; Harder, 1983; Shakeshaft 1987; Van Meir, 1975). Dickerson (1978) stated that perhaps the most formidable barrier to women's full participation in professional and managerial fields is their "own lack of confidence in themselves, regardless of their own abilities" (p. 1). Fitzgerald (1979) stated that the situation of women in educational leadership and administrative positions must no longer be considered declining, dwindling, or stable but critical for the educational well-being of the future for young people. Within the slightly more than twenty-five years since WW II the numbers of women who hold full administrative positions have eroded to a point of national and professional disgrace. (Fitzgerald, 1979, p. 33).

Women who aspire to an educational administrative position within the public school system will need positive self-esteem, a cooperative as well as a competitive spirit and the possession of administrative skills such as organizing, scheduling, supervising, coordinating, staffing, scheduling, budgeting, as well as skills in areas such as interpersonal relations leadership, group dynamics, communication, organizational theory, negotiation, management, and change agent skills 
(Adkinson, 1981; DiBella, 1979; Horner, 1977; Radin, 1980; Truett, 1979; Schetlin, 1979; Shakeshaft, 1987, Van Meir, 1975).

This dissertation explored and examined how the father/daughter relationship impacted upon ten women who now hold administrative positions in the field of education. The intent of this case study was to contribute to the literature regarding women in educational administrative positions by bringing psychological and sociological theory in line with personal experiences of the father/daughter relationship, as viewed in four major phases of development: middle childhood, early and later adolescence, and early adulthood.

\section{Definition of Terms}

The terms in this study are defined below.

Father: One related to another in a way paralleling or suggesting the relationship of father to child (Webster, 1979, p. 828). One who actively participated in the childrearing practices of his daughter during the middle childhood, early and later adolescence, and early adulthood years.

Daughter: A female (child or adult) who is the recipient of the father's contribution to her well being and aspirations in life. Educational Administrator/Leader: A woman who has reached at least the position of principal in either the elementary or secondary level of education within the public school setting. Developmental Tasks: A set of skills and competencies (motor skills, 
intellectual skills, social skills, and/or emotional skills) that are acquired as the person gains increased mastery over one's environment (Havighurst, 1972).

Psychosocial Crisis: Refers to the person's psychological efforts to adjust to the demands of the social environment at each state of development (Erickson, 1980). "The word crisis in this context refers to a normal set of stresses and strains rather than to an extraordinary set of events" (Newman, 1984).

\section{Assumptions}

The relationship between the selected candidate and her father does not demonstrate any infliction of mental and/or physical abuse and/or desertion during any or part of the daughter's middle childhood, early and later adolescence, and/or early adulthood years.

Selected women subjects volunteered to discuss the interpersonal relationship they had with their fathers during their middle childhood, early and later adolescence, and early adulthood years.

Selected women subjects were open about their experiences with their fathers and shared their personal stories with honesty.

Selected candidates were interviewed and committed to one session of taped interview approximately two and a half to three hours. 


\section{Limitations}

The findings of this study represented only ten women who: (a) are members of the San Diego Council of Administrative Women in Education and (b) hold an educational leadership position of principal and/or higher in the San Diego County public school system, San Diego, California.

The experiences of these ten women may not be representative of all women who currently hold administrative positions in the public school system, but their shared experiences will contribute to our knowledge of the father/daughter relationship and the study of human beings in general.

Any researcher embarking on a study of this nature would come to it with his/her own perceptions and memories of the relationship with his/her own parents. Therefore, in order to assure that biases of this researcher did not affect the interpretations of this study, independent consultants Peggy Thomas, M.A., M.F.C.C., a practicing marriage and family counselor, La Jolla, California, and Suzanne Fields, Ph.D., research journalist and author of Like Father, Like Daughter, were selected by this researcher to review the transcribed interviews and interpretations. 
CHAPTER II

\section{Review of the Literature}

\section{Historical Perspective of Fathering}

The family life structure as it appears to us in Western societies today is indeed not a very old concept. The rise of cities, the middle class, and the concept of home as the single family dwelling dates back only to the eighteenth century.

The Industrial Revolution brought a major shift in the way families accomplished their responsibilities toward the family unit. As a result of the "major political shift in family life" (Green, 1976, p. vii) mothers changed from having responsibility of early caretaking to responsibility for childrearing (Stein, 1977; Green, 1976), while fathers changed from influential agents of socialization to economic providers (Lamb, 1981, p. 2).

The traditional role model of the father was now seen as based on the division of power in society. In the traditional family, the son received the higher priority for developing competence, independence, success, and intellectual achievement. The daughter was encouraged to develop such qualities as warmth and tenderness, being attractive and eager to please, as well as attending to the needs of others including 
her father (Gilligan, 1982).

The literature of the 1940's and 1950's, particularly the studies done by Parsons (1955), Aberle, and Naegele (1952) regarding family structure, stated that the primary function and major influence of the father in the family was to teach sex-role differentiation (Rivers, 1979). In the Aberle and Naegele (1952) study, half the fathers interviewed accepted the fact that a career for their daughters was a possibility - "but only as a possibility" (p. 376). The fathers preferred their daughters to marry. Only two fathers out of twenty wanted their daughters to be financialiy independent and these two fathers had wives who worked part of their married lives.

The impact of World War II on the United States and the American family produced "extensive literature on fathers which primarily related to the deletorious effects of his absence" (Keller, 1980, p. 197). The father's absence as a factor as far as girls were concerned was its effect on her sex-role development and her ability to form a heterosexual relationship in later life. The impact of the absent father still was not related to the daughter's ability to develop skills as it was for the son. The major concern of such studies during the 1940 's and 1950's of paternal absence has been with the adequacy of children's personality adjustments and their deviations from normal sex-role development (Barnett, 1978; Fields, 1983; Keller, 1980; Rivers, 1979). The daughter was not considered to be one who had potential to become a leader. Being powerful or having power was not considered a feminine quality. Qualities such as self-reliance, leadership, and 
independence were not consistent with the traditional concepts of good parenting for a mother, let alone a wife. According to Rivers (1979), men did not care whether daughters grew up to be financially independent persons.

By the late 1950's, early 1960's, the literature and research studies dealing with the importance and influence of the father in the family structure diminished considerably, so much so that by the 1970's the limit shifted once again to the mother and her influence on the child's development (Rivers, 1979; Feldman, 1983). The paternal influence in the family structure was again found in the shadows of the literature and research studies (Biller, 1974; Green, 1976; Lynn, 1974). The father was the "most ambiguous figure in the future of the human family" (Green, 1976, p. 12). Through the late 1960's and 1970's, the father continued to be the second-class parent, a concept reinforced by counselors, psychiatrists, psychologists, educators, and the legal system (Adams, 1978; Hami1ton, 1971; Lamb, 1981; Osofsky, 1972; Weinraub, 1978).

According to Weinraub (1978), the view of the father as a secondclass parent is changing as a result of (a) ethnological observations of children in naturalistic settings; (b) new attitudes toward sex roles, (c) increasing stresses on the nuclear family and (d) the rise in alternative childrearing situations. Researchers investigating the family and its complex dynamics are now becoming more aware that the mother is neither the first nor the only influential individual in the child's development (Kotelchuck, 1972; Lamb, 1976; Lewis and Weinraub, 
1976). It has been further recognized that the child grows and exists "within a rich and complex social network, where the father plays a significant part" (Weinraub, 1978, p. 109) influencing and impacting the child's developmental stages. Lamb further states:

it is important to recognize that the father's. role is defined by, and must be seen in the context of, a network of significant relationships within and outside of the family. It is also necessary to see continuity within the life cycle and to recognize that the father-infant, father-child, father-adolescent relationship represent different stages in the evolution of a developing relationship between two individuals (Lamb, 1981, p. 2).

The Father's Influence on His Daughter: An Overview

Perhaps two of the greatest goals a parent strives for is the child's attainment and maintenance of "an independent sense of self and a capacity for intimate relationships" (Stein, 1977, p. 170) Starting with infancy, the father's involvement is crucial to the development of his daughter's autonomous capabilities which in turn provides "a viable foundation for a continued good relationship during the adolescence" (Cath, 1982, p. 227) years and on into adulthood.

In the mid 1960's, "a series of significant theoretical and research efforts has related numerous aspects of a daughter's development to the father's influence" (Hamilton, 1971, p. 81). Collins 
(1983) indicates that:

there was a slow but measureable shift from seeing Dad as the remote, removed breadwinner figure to being someone who shares much more actively in other things involved in taking care of kids from early infancy onward $(p, 20)$.

This renewed interest in the paternal. influence in the family structure, particularly noted in the literature of the 1980's, has been a result of six crucial factors which have exerted pressure on the behavioral scientists to study fathers, the "forgotten contributors to child development" (Lamb, 1981, p. 6). Factor one relates to the fact that the modern father wants to be an integral part of his child's life and socialization process. No longer does the father of today want to be a peripheral figure in the family life structure (Lamb, 1981; Sheehy, 1974). The second factor for the interest in fathers relates to the "mortal danger of displacement of the traditional family structure itself" due to the "rapidity and extensiveness of recent changes in children's rearing environments" (Lamb, 1981, p. 4). A third factor relates to the extensive research studies and theories focused on the mother-infant, mother-child relationship producing an imbalanced perspective of the family structure. This research forced the behavioral scientist to question whether fathers could be "deemed irrelevant entities" (p. 4) in the socialization process of their children. Factor four relates to the latest empirical and theoretical research in cognitive and social development. This evidence demonstrates that the amount of influence a parent has on a child is far 
more significant than the amount of time the parent spends with the child. This influence, factor five, does not necessarily have to be a direct influence on the child. The relationship between the mother and father has an indirect influence on the child as well. In conclusion, factor six relates to the way children are conceptualized. According to Lamb (1981), children are not being portrayed as "passive recipients of social influences" (p. 6) but rather as active participants in the development of their socialization process.

\section{Life Stages}

The continuation of Chapter II will be divided into four life stages: middle childhood, early adolescence, later adolescence, and early adulthood. Each life stage will then be discussed according to the developmental tasks associated with that stage of life. This format coincides with the arrangement of questions presented to subjects during the interview (see Appendix E).

Middle Childhood

For many fathers, the first step may be to realize that men can be parents in the true sense, they can care for and nurture their children from infancy on (Rivers, 1979).

It has been suggested that the daughter's experiences with the father from early infancy through middle childhood years $(8$ to 12 years 
of age) are related to her later ability to trust males, and the ease with which the father and the daughter can accept her fuller sexual development in adolescence (Hamilton, 1971; Saunders, 1985). The establishment, development, and maintenance of trust, autonomy, initiative, and industry (Erikson, 1980) during early and middle childhood are crucial to the personal and professional growth of the daughter.

According to fields, fathers have a special responsibility of responding to their daughters with love, guidance, and admiration. Fields (1983) stated that the father is "a loving escort to the larger world" (p. 76) and needs to assist his daughter during middle childhood years with

1. building wholesome attitudes toward self

2. learning how to get along with peers

3. developing fundamental skills in academia

4. learning an appropriate feminine role

5. developing conscience, morality, and a scale of values

6. achieving personal independence (Havighurst, 1972).

Middle childhood years are spent learning the developmental tasks or fundamental skills that are valued by one's culture or society. "As children gain confidence in their skills, they begin to have a more realistic image of their potential contribution to the larger community" (Newman, 1984, p. 232).

Adjustment during the middle childhood years between the ages of 8 to 12 deals with the developmental tasks of (a) social cooperation: the 
like-sex peer group, (b) self-evaluation, and (c) skill learning and (d) team play. These developmental tasks are intertwined with one's ability to adjust to the psychosocial crisis of industry versus inferiority.

Social Cooperation: The Like-Sex Peer Group

The daily interaction of a child with his/her peers provides an opportunity, appreciation, and sensitivity to (a) differing points of view, (b) a variety of social norms and pressures, (c) experiences of intimacy with a same-sex peer. Although the family still remains an integral aspect of the child's life, the peer group with which one associates now starts to have an impact. "The friendship group is a transitional allegiance between commitment to the family and commitment to the larger social community" (Newman, 1984, p. 234). Self-Evaluation

During early childhood, a child develops the capacity to reflect on oneself as an object - to see oneself from the outside as others might see him/her (Newman, 1984). During the middle childhood years, however, the child "strives to match internalized goals about the levels of attainment" (Newman, 1984, p. 234) he/she hopes to achieve while simultaneously receiving feedback from family members, peer group members, and significant others about the quality of his/her performance.

"One of the most significant variables that will influence the outcome of the child's evaluation is the sense of self-esteem which according to Webster's Dictionary is the belief in oneself (Webster, 
1980 , p. 1292). The child who has a negative sense of self-worth or a great deal of uncertainty about personal worth is more likely to react to risks or novelty with anxiety" (Newman, 1984, p. 213). The child with a strong, positive sense of personal worth will be able to initiate activities, explore the environment, and take risks in behavior (Ellison and Firestone, 1974, p. 657).

One's self-esteem is comprised of three parts: (a) self-confidence, or sense of competence and mastery over one's environment, (b) self-respect or sense of worth, and (c) social acceptance or sense of feeling positively valued by others (Newman, 1984; Barnett, 1978). The content of one's self-evaluation changes with development because of (a) an increased ability to differentiate components of competence, (b) an increased concern with a variety of significant others who may give or withhold approval, and an (c) increased capacity to experience guilt when internal norms for either competence or social acceptance are violated, (Newman, 1984, p. 218).

A child's self-esteem "evolves from an authenticity of feelings based on qualities, aptitudes, and competencies that flow from what has been termed 'the true self'" (Fields, 1983, p. 105). A sensitive, loving father who appreciates, encourages, and supports his daughter's "true-self" and thus validates her very existence will produce a daughter/woman with a mature self-esteem capable of facing and dealing with her own insecurities and at times feelings of powerlessness and helplessness in order to overcome them (Appleton, 1981; Fields, 1983). 
The father's validation will also provide the daughter/woman with the confidence to seek the company and friendship of men in her personal and professional life who appreciate her competencies and attractive feminine qualities (Fields, 1983).

Skill Learning

Middle childhood emphasizes the acquisition, growth, and development of athletic, artistic, and intellectual skills. It is during this life stage that the development of competence is shaped by what people who are significant in one's life expect, reward, punish, and value.

The ability to read, compute mathematical problems, and perform through the media of art and music permits the child "to expand into the world and to supplement feelings of worth through the acquisition of new skills" (Newman, 1984, p. 240). Developing competency and mastery of a wide variety of skills reinforces and enhances the development of achievement motivation.

Achievement motivation as defined by Hamilton (1971) "refers to the ambition to do well, relative to some standard of excellence" (p. 101). Children high in achievement motivation integrate the following four points in their personality: (a) take moderate risks in order to achieve; (b) favor individual achievement over stressing close involvement with the family; (c) take an active position in life, and (d) tend to work toward future goals rather than pursue immediate gratification (Hamilton, 1971).

"One of the basic functions of a parent or caretaker is to provide 
the stability and reassurance that facilitate exploration of novel activities and environmental features and thus foster the acquisition of competence" (Barnett, 1978, p. 14). Studies indicate that a father's attitude and behavior toward his daughter determines his daughter's attitude toward achievement (Hamilton, 1971; Biller, 1974; Lamb, 1981). Fathers who are cold and do not instruct or teach their daughters often produce "ambitious, frustrated, and angry daughters, furious that the world does not recognize them, but unable to make their own way" (Appleton, 1981, p. 73) causing a "number of psychological problems and disorders, initially viewed as a result of inadequacies in the mother's behavior, and now appear to be influenced as much if not more by the father's behavior" (Woolfolk, 1982, p. 59).

"Fathers who are attentive and encouraging of their daughters' achievements without being overwhelmingly affectionate have highly motivated daughters who are willing to take responsibility for their own successes and failures" (Stevens and Mathews, 1979, p.113). Studies of successfur professional women indicate that the fathers of those women had an impact and influenced the advancement of their daughters' self-images and their ability to achieve long after they left childhood behind (Hennig, 1976; Cartwright, 1970; Helson, 1971).

Fields states that "a father's love and admiration for his daughter must be accompanied by his confidence in her ability to make use of practical information, which is to him second nature" (Fields, 1983, p. 39). Lozoff concluded after a four year study that women were "more likely to be self-determining when their fathers treated them as 
interesting individuals, worthy and deserving of respect and encouragement" (Mackay, 1983). Women thus treated by their fathers "did not feel their femininity was endangered by the development of talents" (p. 1).

\section{Team Play}

Active participation as a team member in sports provides an opportunity for the daughter to learn about (a) subordination of personal goals to group goals, (b) the principle of the division of labor, and (c) the nature of competition and the importance of winning (Newman, 1984). Lever stated that socially approved competition improves one's abilities in interpersonal competition, interdependence of teamwork, and leadership skills and "that these organizational skills may generalize to non-play situations (Lever, 1976, p. 478-487). Diamond (1978-1979) continues by stating that team work provides a strong foundation for the development of brotherhood/sisterhood, loyalty, directed focus toward a common goal, and persistence necessary for an administrative/leadership position.

Hennig (1976) attributes the lack of women in leadership/management male dominated occupations in part to the fact that women as young girls were not exposed to or did not have an opportunity due to social norms to actively participate in sports as did boys their own ages. With the onset of organized sports, girls today are experiencing more opportunities to participate in athletic events. "The basic lessons of sports - goal setting, team effort, playing by the rules, persisting to master the skills necessary to compete, realizing that success is 
possible and failure can be overcome" according to Diamond (1978-1979) "have a definite relationship to the skills needed for management and other leadership positions" ( $p$. 60). Diplomacy, sticking up for one's rights and being strong and persistent are also characteristics that can be taught and learned through one's participation in team sports (Mackay, 1983).

Successful women in sports such as golfer Nancy Lopez and tennis player Chris Evert acknowledge that their fathers were strong, nurturing powerful positive influences in their careers (Hunt, 1980). According to Hunt (1980), polls showed "that it was fathers far more often than mothers from whom daughters learned sportsmanship, courage, and respect for hard work (p. 173).

The Psychosocial Crisis: Industry versus Inferiority

A child with a healthy self-esteem is able to (a) demonstrate mastery of her environment, (b) perceive the world and herself realistically, and (c) reflect an integration or "unity of personality" (Fields, 1983, p. 106). The father who offers his daughter positive reinforcement, encouragement, honest constructive criticism, and supports the learning of a variety of skills assists his daughter to develop a strong sense of industry, inculcating the values of discipline and perseverence, making the connection between the self and work at an early age" (p. 106).

\section{Summary}

The father who is warm and nurturant, demonstrating more task-oriented behaviors (Osofsky, 1972; Radin, 1976) and participates 
extensively in childrearing, encourages and fosters greater altruism, moral development, and generosity (Hoffman, 1970). The father's characterisitics are also related to the child's academic performance, establishment of peer relationships, general, psychological adjustment, feelings of self-esteem, and later success in heterosexual relationships (Biller, 1976; Lamb, 1976).

Each newly learned skill further enhances the child's desire to achieve which builds confidence, competence, and mastery over one's environment. Children who constantly experience failure at this life stage internalize a sense of inferiority rather than a sense of industry. Therefore, "a father has to strike a balance between protecting his daughter and helping her go unafraid into the world with the knowledge in which he has armed her" (Fields, 1983, p. 39).

\section{Adolescence}

Father-daughter love rests upon a delicate fulcrum with an exquisite balance (Fields, 1983).

The teenage years are filled with inner conflict and turmoil not only for the daughter, but the father as well. Appleton (p. 181) considers this period of time one of conflict. The daughter ponders her own identity, and tries to deal with issues in achievement toward:

1. new and more mature relations with agemates of both sexes

2. a feminine social role

3. emotional independence from parents and other adults

4. selecting and preparing for an occupation 
5. developing intellectual skills and concepts for civic competence

6. preparing for marriage and family life

7. socially responsible behavior (Havighurst, 1972).

The father is about to enter or is in his midlife adulthood years (Appleton, 1981; Turner, 1979). This is a period of time which is one of introspection, self-evaluation, and re-structuring of one's life (Levinson, 1978; Turner, 1979). While the father's conflict is one of generativity versus stagnation, the daughter's conflict is group identity versus alienation in early adolescence and individual identity versus role diffusion in Tater adolescence (Erikson, 1980). In essence, the father and daughter are both in the process of determining their own destinies.

Saunders (1985) stated that many women who have problems with their fathers can trace the beginnings back to the onset of puberty. Indeed, "adolescence most dramatically brings out iconoclastic crises for a father and daughter" (Fields, 1983, p. 111). "However, fathers who manage to contain the storms of their children's adolescence seem to develop an attitude of initiating their children into the adult world, welcoming them as adults, not fending them off as dreaded rivals" (Green, 1976, p. 124).

A father, according to Rivers (1979), can provide his daughter with a bridge from early childhood, through adolescence to the adult world. 


\section{Early Adolescence}

Early adolescence (13 to 17 years of age) is the time when puberty brings forth many psychological and physiological changes which (a) bring adolescents closer to an image of themselves as adults, (b) influences sex-role identification, and (c) creates a more narcissistic or self-involved individual (Newman, 1984).

Adjustment during early adolescence deals with the developmental tasks of: (a) physical maturation, (b) formal operations, (c) emotional development, (d) membership in the peer group, and (e) heterosexual relationships. These developmental tasks are interwoven with one's ability to adjust to the psychosocial crisis of group identity versus alienation. Physical Maturation

One's acceptance "of the physical changes that take place during adolescence seems to require adequate information about the meaning of these events, a positive identification with one's sex role, and an atmosphere of family and peer support" (Newman, 1984, p. 281).

Fields stated that "how a father acknowledges the almost daily changes in his daughter's body and how she accepts his admiration, how he responds to her boy friends and her developing sexuality, how she reacts to him during these hectic changes, become the crucible of adolescence" (Fields, 1983, p. 23). A father needs to show his respect for his daughter's "newly acquired self-consciousness" (p. 136) regarding her appearance. A warm, accepting father who is not too 
frightened of his daughter's sexual development will assist his daughter to feel more comfortable, accepting, and secure of her own physical changes as well as capable of attracting the opposite sex (Appleton, 1981 ; Fields, 1983).

An inattentive father who feels unsettled and/or is frightened by his daughter's body and sexuality, and the daughter who is unaccustomed to talking to or arguing with her male parent, may never acquire the savvy needed to size up a man as well as being handicapped in selecting a husband and/or "ill equipped to negotiate problems which arise in love" (Appleton, 1981, p. 40) and work.

\section{Formal Operations}

Early adolescence is an age of enlightenment about the reality of the world in new ways. Concrete thinking becomes more abstract, generating "hypotheses about events that they have never been perceived" (Newman, 1984, p. 281).

Douvan (1963) noted in her studies that adolescent girls had a vague appreciation of the realities of the adult world. Rivers (1979) stated that "at this age girls should be introduced to the realities of and be allowed to explore the economic, political, and social aspects of the world outside the home" (p. 175). According to Fields, it is the responsibility of the father to "introduce his daughter to the larger world, to help her meet and learn to know others in a safe environment beyond the family" (Fields, 1983, p. 36).

The father is the parent most involved with:

long range goals of the kind that concern daugther as she 
steps across the threshold of home and sees the world expanding beyond the horizon. The tests with which the new world confronts her loom more formidable than her skills, and she needs a yardstick to measure herself against the unfolding opportunities (Woolfolk, 1982, p. 39).

Emotional Development

A major task during early adolescence is gaining tolerance for one's emotionality (Newman, 1984). A father who offers simple companionship, guidance, and hope in his daughter's future enhances the trust factor of the father/daughter relationship and allows for further development of healthy coping skills in order to deal with the emotional intensities in the developmental growth of his daughter (Kahn, 1981). Modeling and mentoring become critical aspects of the father/daughter relationship (Fields, 1983; Kahn, 1981).

Membership in the Peer Group

"If relationships with parents are crucial to a girl's sense of competence at adolescence, her relationships to peers in the peer culture is also important" (Rivers, 1979, p. 154). The peer groups during early adolescence "tend to become more structured and organized entities than they were previously" (Newman, 1984, p. 285) having more clearly defined purpose and meaning for the adolescent. Participation in a particular group may depend on one's own popularity and acceptance by that group based on academic and/or athletic ability, social class, future goals, ethnicity, and/or religious affiliation.

"For girls, especially for the achievement-oriented among us, 
adolescence often brings with it a traumatic switch in the definition of competence. Success becomes identified with popularity, with being the most sought-after girl in the group (Hennig, 1976, p. 125). Heterosexual Relationships

Relationships with the opposite sex during early adolescence "provide the initial context for sexual activity" (Newman, 1984, p. 289). A father's willingness to discuss men's feelings and attitude regarding heterosexual relationships can help "demystify the whole question of sexuality" for his daughter (Rivers, 1979, p. 186). Open and honest lines of communication only enrich and enhance a daughter's qualities of autonomy, trust, ambition, initiative, creativity, and the capacity for intimacy with other men (Fields, 1983).

The Psychosocial Crisis: Group Identity versus Alienation

As transition occurs from middle childhood to early adolescence pressures are exerted from the family, age-mates, and school to ally oneself with a group of peers (Newman, 1984). Conflict arises in the home when the early adolescent's friends do not reflect the values of the parents. Both mother and father must learn to release the ties that bind the daughter to dependency on the family by allowing the daughter freedom, with guidance, to choose her same sex and opposite sex friends and/or groups (Fields, 1983). "For the first time, a resolution of the psychosocial crisis depends not on the relationship of an individual to an adult in the environment but rather heavily on the interaction of an adolescent and peers" (Newman, 1984, p. 295). 
Later Adolescence

In later adolescence (18 to 21 years of age) autonomy from parents, sex-role identity, internalized morality, and career choice are the developmental tasks being mastered while at the same time adjusting to the psychosocial crisis, individual identity versus role diffusion. According to Erik Erikson, it is the final stage of childhood. It is a time when the individual "will be compelled to make a wide variety of relatively permanent choices about their lives" (Newman, p. 184, p. 318).

A father can provide his daughter with a bridge from adolescence to the adult world by working on and through the developmental tasks of: (a) autonomy, (b) sex role identity, (c) internalized morality, and (d) career choice which are interwoven with one's ability to adjust to the psychosocial crisis of identity versus role for the later adolescence life stage. Autonomy

Erik Erikson stated that one of the most critical aspects of late adolescence involves the task of identity formation where there is the "eventual commitment to a personal integration of values, goals and abilities" (Newman, 1984, p. 318). Developing autonomous thoughts and actions is most often viewed when the child moves out of the home and becomes an independent member of our society.

For one to fully develop a "psychological sense of autonomy, individuals have to realize that they are approaching the end of 
childhood" ( $p .320)$. The father's involvement in the daughter's autonomous capabilities "provides a viable foundation for a concinued good relationship during adolescence, when the more powerful force of sexuality and the struggle to affirm a more separate identity necessitate a greater distance between them in other areas" (Cath, 1982, p. 227).

The father's care and interest during this stage "not oniy support the daughter's initial strivings toward autonomy and independence by" forming a bedrock of secure identity away from the mother, but also represent for the daughter an important early experience of "differentness" (male instead of female) from the mother and the self" (Cath, 1982, p. 226; Fields, 1983, p. 18; Hennig, 1976, p. 127). This, according to Cath, helps the daughter to differentiate her own identity from that of the mother and to expand her eventual choice of the adult traits and behaviors with which she can identify" (Cath, 1982, p. 228). How the father assists his daughter to separate from her mother and from him will depend on the father's awareness level and desire of the father to separate from his daughter (Fields, 1983, p. 40). If a father respects his daughter's feelings, if he loves her for who she is and not for what he needs, her opportunity to develop into an independent person becomes much greater (Middleton-Moz, 1986). The emotional security of the father's trust in the daughter's ability to behave autonomously reduces the likelihood that she will succumb to pressure from peers, i.e. boyfriends and/or significant others in the environment when she is uncertain or unwilling (Rivers, 1979, p. 203). 
Scientific evidence has been presented that "women who identify with their fathers or with the male role as society presents it turn out to be high in self-esteem and autonomy, and the ability to act independentiy" (Rivers, 1979, p. 15). One's self-esteen is directly related to establishing an identity that clarifies who I am, and where I belong ( $p .164)$.

Self-esteem is made up of two parts: self-confidence (competence) and self-respect and social acceptance (a feeling one is worthy or worthwhile). Self-esteem is not a conscious, verbalized judgment but a constantly experienced automatic part of every other feeling. It is the conviction that one is competent to judge, think, and correct one's errors (Appleton, 1981 , p. 106).

It is a feeling of being "positively valued by others and a sense of mastery over one's environment" (Barnett, 1978, p. 19). It is the integration of one's values, goals, and abilities. Sex Role Identity

The societal placement of a negative value upon female sex-role stereotype was pointed out by a recent survey of psychiatrists, clinical psychologists, and social workers. The survey revealed that the characterisitcs used to describe an unhealthy, immature adult were found to be descriptions of a normal female adult (Boverman, 1972). Women in Hennig's (1976) study learned through peer group experiences, society, and teacher attitudes and comments about sex 
distinctions. These "distinctions were inconsistent with their parents, particularly their fathers' points of view" (Hennig, 1976, p. 112), a view these women choose to keep. Although masculine/feminine role dichotomy become increasingly clear as these women entered college they still gained strength in their concept of tehmselves clarifying their values, goals and abilities. These women were able to "synthesize their own concept of themselves and what they could do with society's traditional view of women which depended heavily on that crucial confirmation of their right to be more than tradition and society prescribed" (Hennig, 1976, p. 106).

A father plays a critical role in a "daughter's perception of achievement, competence, and ambition" (Field, 1983, p. 279). Through his active participation in his daughter's life, he demonstrates that the qualities of achievement, competence, and ambition are not incompatible with femininity. A father who is inattentive does not provide his daughter with skills and experience to feel comfortable or successful in a relationship with another man. Studies have shown "significant relationships between father absence and father acceptance and the daughter's ability to interact with males, her personality adjustment, and her social and sexual self-esteem, and her heterosexual behavior" (Musser, 1983, p. 907).

Fields noted that it is a rare father who can fuse admiration for a daughter's femininity with pride in her other capabilities such as autonomous behavior, ambition, creativity, initiative. The father's admiration and affection for his daughter provide "a balanced 
perspective for love and work" (Fields, 1983, p. 94) and further development of trust and admiration for the opposite sex (Friedman, 1985; Romano, 1980).

Internalized Morality

"Early moral development involved the gradual internalization of parental values and standards" (Newman, 1984, p. 194). At the early school age years (5-7 years of age) children learn, internalize, and respond appropriately or inappropriately to the moral codes of the family and the community. They learn that the difference between right and wrong has its rewards and/or consequences for certain types of behavior. During later adolescence one becomes more aware of the "multiple perspectives that are possible in a moral situation, and of the principles of justice and fair play that need. to be preserved in a moral decision" (p. 329). As one becomes more autonomous and interacts with the world outside the family unit, the more recognition there is to the wide variety of subcultures that interact with one's own moral code.

Musser (1983) stated that the "quality of the father-child relationship appears to be related to the child's sex-role development, cognitive development, moral development, and achievement motivation" (p. 907). Fathers who provide "positive evaluation, express affection, provide emotional support, provide equalitarian treatment, as well as firm limits and structure for their daughters will tend to have daughters who rate themselves as having high levels of personality adjustment" (p. 913.) Baumrind and Black (1978) and Coppersmith (1967) also concluded in their studies that there is a positive relationship 
between a father's love, acceptance, amount of control the father exerts on his daughter and the increase of the daughter's ability to reach higher levels of self-esteem, self-reliance, assertiveness, contentment, and self-control. "If the woman has not developed an inner set of controls, if she has simply bought her parents' values with no questions asked, the growth of her sense of self may be severely impaired" (Rivers, 1979, p. 150).

Career Choice

One way of expressing and establishing commitment to one's identity in our society is through the selection of an occupation which "sets the tone for the early adult life-style" (Newman, 1984, p. 333). The development and acquisition of competence in and for a chosen occupation begins with the selection "of those features in the environment that provide information about success and failures, and going on to use that information to generate new plans" (Barnett, 1978, p. 14).

Studies have shown that fathers who placed high emphasis on their daugther's developing skills and abilities rather than on a socially defined sex role or behavioral style provided their daughters with great emotional security and coping skills to survive in their chosen occupations (Barnett, 1978; Hennig, 1976; Rivers, 1979; Woolfolk, 1982). Upon review of the biographies of successful professional women it was found that in many instances fathers influenced their daughters' advancement of their self-image and the ability to achieve (Biklen, 1980, p. 200). According to Rivers (1979), "the messages fathers send their adolescent daughters often give girls clues about the importance 
of the work they will do in life" (p. 154). Woolfolk (1982) stated that psychologists have just begun to realize how much a father determines his daughter's attitude toward achievement. Hamilton observes that "a number of psychological problems and disorders, initially viewed as a result of inadequacies in the mother's behavior, appear to be influenced as much by the father's behavior" (Woolfolk, 1982, p. 59)

Rosen's (1977) study showed that student teachers who hoped to eventually become educational administrators, supervisors, or college teachers almost invariably described their childhood selves in terms as reflecting a coping, self-initiating, independent orientation. However, those student teachers who hoped to continue to teach children until retirement recalled their childhood as a time when life happened to them for better or worse rather than one they had lived actively and by their own initiative. "When a father does not value a daughter's developing competencies, when he does not respond to her femininity, she must seek for herself, and with greater difficulty, what should have been hers by inheritance" (Fields, 1983, p. 28). Whether a women enters the world of work as a child, adolescent, or as an adult psychologically affects the course of her career (Appleton, 1981).

Consequences of economic dependence of women become visible oniy when it becomes a social issue and involves taxpayers' money: when a woman goes on welfare, when a pregnant teenager has nowhere to go, when a poor elderly widow can't find a place to live, when a battered woman with children desperately seeks food and shelter. These situations are products of 
those factors that seem built into the lives of many women: economic dependence and occupational "incompetence" (Rivers, 1979, p. 237).

The Psychosocial Crisis: Individual Identity versus Role Diffusion Individuals who have resolved the crisis between individual identity and role diffusion have a well "integrated identity, which includes a definition of themselves as sexual, moral, and political participants" (Newman, 1984, p. 356). Commitments are made to specific values and goals in one's life which serve "as a basis fo later life decisions" (p. 356).

A father who participates in the development and believes in his daughter's ability to establish and enhance her own competencies can help her develop a strong sense of industriousness thus inclucating the "values of discipline and perseverence, making the connection between the self and work at an early age" (Fields, 1983, p. 106). Fathers who are cold, have high expectations for their daughters, and who do not instruct "often produce ambitious, frustrated, and angry daughters, furious that the world does not. recognize them but unable to make their own way" (Appleton, 1981, p. 73). 


\section{Summary}

Adolescence is the time "when the self, already given much of its shape by earlier experiences, takes on the form that will travel through adulthood" (Rivers, 1979, p. 39). It is a time when there should be open and clear lines of communication and set limits and expectations a) lowing for expression of anger, frustration, concerns, and inner conflict without fear of retribution. The type of environment further develops the daughter's sense of confidence and stability encouraging internalization of morality and self-reliance (Newman, 1984).

Mennig (1976) stated that during this period of time the "most important source of support and confirmation of these women's developing self-concepts and their most important source of reward in adolescence lay in the father daughter relationship." (p. 127).

The crucial events at this time in a girl's life will determine one of two paths she will select to go down: "one that leads to self-actualization and a strong sense of self, to competence" or "to a more passive, acquiescent role in life in which she is more acted upon than active" (Rivers, 1979, p. 138-139).

A father can be "a vehicle through which a daughter arrives at an idea of her true worth" (Woolfolk, 1982, p. 35). "A girl lucky enough to have an involved father during this stormy yet lovely time is much benefited by his authoritative guidance in learning how to deal with men and in the development of her own self-esteem. As he copes with and negotiates the tricky shoals of adolescence with her she learns from 
him. The incorporation of his strengths build up her own. She learns to be confident about her ability to conquer complicated and difficult new situations by watching and learning as the father interacts with her. Leaving home for college and preparing for a life goal involves fear, ambivalence and mourning. "The process takes varying amounts of time depending upon the strength of the woman, her psychological maturity, and the support of her parents" (Appleton, 1981, p. 20).

Early Adulthood

What we need are fresh examinations of womens' lives -- from which can be drawn new theories of how women can live and grow, not merely conform and decline (Rivers, 1979).

Early adulthood years (22 to 34 years of age) reflect the establishment of one's style of life that serves "as a framework for the organization of experience during the rest of adulthood" (Newman, 1984, p. 366). One's ability to balance work and leisure time, establish friendships with varying degrees of intimacy, the ability to gauge the tempo of activities in one's life as well as select activities that "reflect the individual's value orientation" (p. 366) emphasize the developmental tasks encountered during the stage of development. The psychosocial crisis during this stage of development concerns itself with intimacy versus isolation.

In studies by Cartwright (1970), Helson (1971), and Hennig (1976), it was found that women who succeeded in the field of medicine, business 
and math had close and very supportive relationships with their fathers. "The relationship between father and daughter produced a special combination of love, admiration, and emulation" (Noel, 1983, p. 124) for such women as Yvonne Burke, former California Congresswoman; Patricia Walker Shaw, president of Universal Life Insurance Company; singer Roberta Flack, Indira Gandhi, and Madame Curie. Cath (1982) stated that women who emphasize their father's contribution to their enthusiasm in work and life usually stress the following aspects of their relationships :

1. his treatment of her as an interesting person in her own right (this is often put in nonsexist terms such as "he didn't see me as just a girl")

2. his trust in her developing autonomous capacities during joint endeavors

3. his own capacity for excitement or enthusiasm about discovery in work or play

4. his invitation to her to participate in areas of mastery with him

5. the emulated quality of his relationship to others, such as colleagues or friends, associated with work in the outside world (p. 227).

Adjustment during early adulthood between the ages of 22 to 34 deals with the developmental tasks of (a) and (b) marriage and childbearing, (c) work, and (d) lifestyle. These developmental tasks are interwoven with one's ability to adjust to the psychosocial crises 
of intimacy versus isolation.

Marriage and Childbearing

"The concept of male as the protector and female as the protected has traditionally been presented in the socialization process of young children. The female child is encouraged to be dependent and the male independent" (Bradwick, 1971). Hennig (1976) found in her study, however, that the twenty-five women in Hennig's study saw marriage and career as an either/or choice. "They chose to reach for more than the traditional woman's role would allow and in their 20 's put aside most of their romantic yearnings." Fathers encouraged their daughters to resist cultural instructions and reach for the freedom of choice in all areas of their lives. None of these women married until they were in their middle 30 's.

The most vital individual in the women's lives during their early 20 's was the relationship these women had with their bosses, who picked up right where their fathers left off. "Once in the protective custody of this mentor, each of the subjects subordinated all other relationships to it" (Hennig, 1976, p. 35). These women accepted their femininity and female role in society on their own terms. This point was also demonstrated during their college days when all twenty-five women in the study rejected sorority living because it was traditional and unsupportive of the kind of woman they wanted to be.

Feidman (1983) stated that:

it is essential for all women to analyze their relationships with their fathers because roles in marriage become fixed in 
the early stages and become more difficult to change as time goes on. Those of us who don't resolve problems with our parents will have difficulty resolving problems with our husbands and lovers. A woman who harbors bad feelings toward her father will spend her days emotionally attached to him. Because of that bond, she won't be free to find significant men who will fulfill her. She'll want unending approval, attention, love; she' 11 demand money, flattery; and she' 11 refuse to accept criticism. Unless she cuts that tie, she may never drain her reservoir of hurt feelings (p. 1630).

Work

"Work is a complex concept in our society" (Newman, p. 376). It involves the learning of (a) technical skills, (b) who are the authority figures in the organization and their relationship to oneself, (c) the norms and hazards of that particular job, and (d) the degree of competitiveness and cooperation involved in interpersonal relationships.

"Usually it is what her father gave her that affects the way a woman enters the work world more than her mother's influence, although the latter is also very important (Appleton, 1981, p.72). According to Appleton (1981) there are two ways a father's influence exerts itself on the daughter's world of work: (a) first is the level of development she has achieved and the degree to which she has separated from her father; (b) concerns the way he perceives and encourages her and the example he sets.

From earliest childhood girls are rewarded for behaviors 
appropriate to particular female adult roles and consequently do not learn behaviors and skills that are essential to success in management of large organizations. From childhood on, the twenty-five women in Hennig's (1976) study:

were taught, encouraged and supported by father, who expected them to aspire to and prepare for a career; who passed on to them their own view of a career as an integral part of a person's life; who deals with them on the basis of an unquestioned assumption; that they would work, just as a man would do, for the greater part of their adult lives (p. 144). Lifestyle

"The concept of lifetyle is an umbrella for the variety of patterns of activities, commitments, and satisfactions that make up adult experiences" (Newman, 1984, pp. 383-384).

Women in Hennig's (1976) study chose their fathers as significant role models, expressed their dislike of traditional female roles, majored predominantly in a professionally oriented area, established much closer relationships with their male peers than with other women; chose careers related to their fathers, and worked almost exclusively in the company of men. These choices set the stage of the future. Fields (1983) stated that "the two values most strongly influenced by a father are a woman's femininity -- her sense of herself as a woman; and her competency -- her sense of herself as an accomplisher" (Washington Post, 1983). 
The Psychosocial Crisis: Intimacy versus Isolation

"Intimacy is defined as the ability to experience an open, supportive tender relationship with another person, without fear of losing one's own identity in the process of growing close. Intimacy implies the capacity for mutual empathy and mutual regulation of needs" (Newman, p. 384). Isolation is the lack of one's mutual understanding and support of another's physical, emotional needs, and of one's life goals. The father who "violates the psychological and sometime physical boundaries of his child" ... "satisfying his own need for self-regard and nurturing" (Middleton-Moz, 1986, p. 92) leaves his young adult daughter with an inept ability to cope with a variety of emotional and intimate encounters at this stage and future stages to follow. Hunt (1980) found that:

the men most pleased with themselves are those who had been most active in caring for their infant daughters, spent the most time with them throughout their childhood, played with them the most, and had been the most loving and affectionate. We determined that the least satisfied fathers were those who rated themselves as most deficient in all categories. These same fathers were also most critical of their daughters and the most apt to name ways in which they as fathers, had failed them (p. 101). 
A father influences his daughter by building a bridge she can cross that is bound together with an abundance of nurturing and emotional support from infancy/early childhood to middle childhood, through adolescence, and on into early adulthood thus encouraging her independent self and the capacity to develop meaningful relationships with others.

The quality of emotional engagement between father and daughter frequently remains as a powerful undercurrent giving directions to that particular vision of happiness which becomes a guiding force in a woman's life and affects her perception of the value of futility of her efforts in striving toward it (Cath, 1982, p. 220). 
CHAPTER III

\section{Research Design}

\section{Case Study Method}

This research is concerned with the identification of the paternal behavior patterns/interactions that: (a) assisted the daughter to grow and mature through the developmental tasks and psychosocial crises during the life stages of middle childhood, early and later adolescence, and early adulthood and (b) encouraged and motivated the women to become teachers and eventually administrators in the field of education. This study also identifies the commonalities and/or differences of paternal parenting styles between the ten selected subjects. The case study method was determined to be the most desirable method available to elicit the results desired for this research paper.

Mauch and Birch (1983) state that the case study is a research design

in which the background, development, current conditions, and environmental interactions of one or more individuals, groups, communities, businesses or institutions is observed, recorded, and analyzed for stages or patterns in relation to internal and external influences (p. 72). 
This case study involved the collection of data from the Dissertation Interview Information Sheet (see Appendix D) and interviews in order to produce an in-depth understanding and appreciation of the inner dynamics of the father/daughter relationship and the impact of that relationship upon women in administrative leadership positions within the San Diego County public school system.

Other research designs such as a survey or quantitative study would not provide this researcher with (a) immediate feedback, (b) the flexibility to change the direction of questioning in order to go deeper into the subject matter and/or (c) an opportunity for follow-up questions for clarification with regard to terminology, events, situations, and feelings (Borg and Gal1, 1983). Stake (1978) believes that the case study research design through its illustrations and words provides a more effective means of assisting the reader to understand the topic under discussion. Yin (1984) concludes by stating that "a case study is an empirical inquiry that:

1. investigates a contemporary phenomenon with its real-life context; when

2. the boundaries between phenomenon and context are not clearly evident; and in which

3. multiple sources of evidence are used (p. 23). Population

In March, 1985 the governing board of The San Diego Council of Administrative Women in Education granted permission to this researcher to obtain data for this case study from its membership. 
Data collected from the Dissertation Interview Information Sheet (see Appendix D) and responses to the Interview Questionnaire (see Appendix E) were obtained from those women members who hold eduational administrative leadership positions in the public school systems in San Diego County and who are also active members of The San Diego Council of Administrative Women in Education, an organization located in San Diego, California which draws its members from San Diego County public and private schools and colleges. It is an affiliate of The National Council of Administrative Women in Education whose purpose is to advance the cause of education and the role of women in administration and supervision.

Pre-selected Candidates

In April of 1986, the San Diego Council of Administrative Women in Education had a total membership of approximately two hundred eighty-eight members. According to membership application forms, one hundred seventy-three members were in administrative leadership positions and one hundred fifteen members of the total membership were considered to be in nonadministrative leadership positions. Of the one hundred seventy-three members in administrative leadership positions, ninety were in administrative leadership positions of principal or above. These ninety members for purposes of this dissertation were considered the pre-selected candidates.

\section{Selection of Pilot and Sample Subjects}

The organization agreed to notify the total membership of this research study via a short article in the May 1986 newsletter - Advance 
(see Appendix A). Onty those pre-selected candidates, ninety (90) members who currently held administrative leadership positions of principal and/or above received in their newsletter an insert entitled Dissertation Interview Information Sheet (see Appendix D). Attached to each insert was a self-addressed stamped envelope addressed to this researcher in care of the University of San Diego. Each of the ninety pre-selected candidates had an opportunity to respond to four questions on the Dissertation Interview Information Sheet which provided this researcher the means to select the appropriate two pilot subjects and ten sample subjects to be interviewed for this case study.

of the ninety pre-selected members who were sent the Dissertation Interview Information Sheet thirty-two were returned to this researcher. Upon receipt of thirty-two (32) Dissertation Interview Information Sheets, this researcher made personal contact by telephone to the pre-selected candidates who responded to the insert in the newsietter Advance. This contact informed the pre-selected candidates of the following: (a) their Dissertation Interview Information Sheets had been received by this researcher; (b) selection of the two pilot and ten sample subjects would be forthcoming and notification of that selection would be made by telephone by this researcher no later than the middle of June 1986; (c) interviews would commence about July 1, 1986; and (d) if they were not selected to be interviewed for this study each respondent would receive a letter stating said fact.

By June 30, 1986, the following points were accomplished by this researcher: 
1. a second telephone call was made to all twelve candidates who had been selected to participate as either a pilot subject or sample subject

2. dates, times, and locations for candidates to be interviewed were arranged

3. letters were sent to all other candidates who were not selected to participate in the interviews (see Appendix B).

The criteria used for the selection of the two pilot subjects was based on the following:

1. candidate was currently in a position of administrative leadership and had previous teaching experience before entering administration

2. candidate's father was currently living at the time of the interview.

The criteria used for the selection of the ten sample subjects was based on the following three points:

1. candidate was currently in a position of administrative leadership and had previous teaching experience before entering administration

2. candidate's father was currently living at the time of the interview

3. candidate's selection of descriptive adjectives for the father were of a positive nature.

These three criteria were selected for the following reasons:

1. they would adequately address the research questions aimed at a 
particular population:

(a) women who held administrative/leadership positions of principal and/or above

(b) women whose fathers were living at the time of this study and

(c) women who had positive relationships with their fathers during the middle childhood, early adolescence and later adolescence, and early adulthood years.

2. It was assumed that if the fathers were deceased, women would have reported their life experiences with their fathers differently thus possibly contaminating the outcome of this research study.

3. It was assumed that candidates who selected positive adjectives to describe their fathers had a supportive caring father/daughter relationship and candidates who selected negative adjectives to describe their fathers had non-supportive, non-caring father/daughter relationships. This researcher recognizes that some conflict between a father and daughter naturally exists in a healthy family unit. The effect, however, of a dysfunctional family on a child is different than on a child who came from or who grew up in a healthy family unit. Working through the developmental tasks and psychosocial crises would be dealt with in different ways, thus the process toward achievement would also be different. This researcher, therefore, did not feel qualified to interpret 


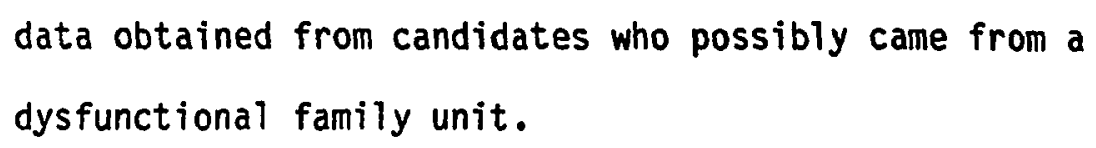

\section{Data Collection Procedures}

Dissertation Interview Information Sheet

The Dissertation Interview Information Sheet (see Appendix D) for this case study was designed to assist this researcher select two pilot subjects and ten sample subjects to be interviewed for this case study. The four questions provided information regarding the following:

1. geographic location of middle childhood, early and later adolescence, and early adulthood years.

2. birth order, name, age, occupation, and level of education of family members: mother, father, and siblings.

3. selection of eight adjectives that best described the father.

4. selection of eight adjectives that best described the mother (see Appendix D).

Only those pre-selected candidates who (a) responded to the Dissertation Interview Information Sheet, (b) expressed a desire to participate in this case study, and (c) circled positive descriptive adjectives regarding their fathers were selected to be either a part of the pilot sample or the ten sample subjects.

The responses to the Dissertation Interview Information Sheet permitted: 
1. comparisons of pre-selected candidates to determine two pilot subjects and ten sample subjects.

2. this researcher to compare and determine particular patterns of commonalities and differences between the ten sample subjects in relationship to location of family during middle childhood, early and later adolescence, and early adulthood, birth order of the respondent, occupation and level of education reached by parents and siblings (see Table 3 on page 72).

3. comparison of ten sample subjects' eight descriptive words selected to describe their fathers (see Table 4 on page 77).

4. comparison of ten sample subjects' eight descriptive words selected to describe their mothers (see Table 5 on page 78).

The descriptive adjectives selected for the Dissertation Interview Information Sheets were obtained from The Adjective Checklist Manual (Gough, 1965), section 27, Masculine attributes; section 28, Feminine attributes; section 29, Critical Parent; section 30, Nurturing Parent; section 31, Adult. The actual selection of adjectives for the Dissertation Interview Information Sheet were chosen by this researcher with suggestions from Susan M. Zgliczynski, Ph.D., Director of this dissertation, and Peggy Thomas, M.A., M.F.C.C., a practicing marriage and family counselor, an independent consultant for this dissertation. Women were not selected to be sample subjects for the following reasons: (a) fourteen women had fathers who were not living, (b) three women were not interested in being interviewed after the initial phone conversation, and (c) two women circled descriptive adjectives to 
describe their fathers that were not of a positive nature.

\section{The Interview}

The implementation of this case study and main source of data for this study was carried out through the process of the interview. This research tool provides:

a process of dyadic communication with a predetermined and serious purpose designed to interchange behavior and involving the asking and answering of questions (Stewart, 1974, p. 3).

The purpose of the interview as a research tool for this case study was to collect data through direct verbal interaction between two individuals; in this case between the daughter (the woman who has reached an educational administrative leadership position) and the interviewer.

Advantages to the Interview

The interview provides the following advantages:

1. adaptability: the interview can alter the interview situation when necessary and adapt questions to the experiences expressed by the interviewee

2. follow-up leads: the interviewer can easily return to or delve further into a particular question when needed

3. provides motivation: the interviewer can carefully motivate the subject and probe further to retrieve more specific responses 
4. control: the interviewer can control the pacing of questions, kind of questions, and responses

5. observation of non-verbal communication: the interviewer can observe body and facial expressions which can add further validity or credibility to one's testimony

6. feed-back: the interviewer receives immediate feedback to questions posed to the interviewee (Borg and Gall, 1983; Gordon, 1980; Stewart, 1974).

The framework of interviewing provides a specific form of observation, participation, and empathizing by both parties (Gorden, 1980).

\section{Disadvantages of the Interview}

The disadvantages of using the interview technique as a research tool are:

1. misuse: other research tools/techniques may elicit more or better research results such as surveys or questionnaires

2. bias: the adaptability and flexibility of the interview could allow for more subjectivity and possible bias than another method of obtaining collected data (Borg and Gall, 1983; Gorden, 1980; Stewart, 1974).

\section{The Interview Guide}

The interview guide provided this researcher "with a conceptual map of the areas to be covered and a convenient way of recording the 
progress of the interview" (Gordon, 1980). The interview guide, therefore, provided the means of obtaining data necessary to meet the specific objectives of the case study and "standardizes the situation to some degree" (Borg and Gall, 1983, p. 441).

The interview guide for this research study was semistructured which allowed for more reasonable objectivity than an unstructured interview, while at the same time, according to Borg and Gall, permitting a more thorough understanding of the respondent's opinions and the reasons behind them.

The semistructured interview is generally most appropriate for interview studies in education. It provides $a_{\text {, desirable }}$ combination of objectivity and depth and often permits gathering valuable data that could not be successfully obtained by any other approach (p. 442).

The research questions for this study stem from three sources which Rossi (1984) stated require the use of the case study methodology. These sources are used when (a) the phenomenon or behavior in question is relatively unstudied and the researcher wishes to try to understand its dimensions and generate hypotheses for further experimental work, (b) the phenomenon or behavior is rare, either with a person or across people, thus precluding the study of large groups of people unless the study is heavily funded, (c) an experimental, laboratory, or intervention study has been conducted on a large sample and discovered findings need to be examined in depth for further clarification (Rossi, 1984, p. 1). 
Rossi (1984) further stated that the case study is characterized by depth of observation and multiple observations with either the same or a different measurement instrument. The number of contacts available to this research allowed the opportunity to check and recheck the data for consistency which according to Rossi should result in valid conclusions.

The development and structure of the research questions for this study focused on Erikson's developmental tasks and psychosocial crisis for the middle childhood, early and late adolescence, and early adulthood life stages (see Appendix E). Questions were developed that specifically related to each developmental task which ranged from a minimum of four to a maximum of eight questions per task. Questions were selected and/or determined by the following: (a) this researcher, (b) Peggy Thomas, M.A., M.F.C.C., independent consultant for this dissertation, (c) readings from Development Through Life: A Psychosocial Approach by Newman and Newman (1984). Other source studies (Fields, 1983; Cartwright, 1970; Costantini, 1972; Hennig, 1976; Helson, 1971) provided this researcher with further support and information regarding the development of the interview guide.

Rossi (1984) stated that the case study is enhanced if, at about half way through the data collection, a knowledgable, non-involved third party is brought in to listen to tapes or read manuscripts of the interviews. The purpose of this intervention is to check that the researcher is not becoming too focused on certain areas and missing important information. The pilot study, therefore, assisted this researcher to examine the interview guide to determine the need for 
revision of questions, addition and/or deletion of questions to be asked of the sample subjects.

Upon review and discussion of the two pilot subjects' transcripts by this researcher with Peggy Thomas, M.A., M.F.C.C., independent consultant and the Dissertation Committee Members, it was decided not to make any changes with the interview guide.

The discussion of each life stage, middle childhood, early adolescence, later adolescence, and early adulthood, began with two introductory questions which were intended to set (a) a time frame of reference for the subject and (b) an emotional tone/awareness for that time period.

1. If your father were talking to his best friend about you during this life stage between the ages of 8 and 12, what would he have said about you?

2. If you were talking to a friend at this time in your life, how would you have described your father? Or what would you have said about him?

Following these two questions the subject was asked questions that pertained to the developmental tasks related to a particular life stage under discussion, i.e. middle childhood, early and later adolescence, and early adulthood. Each life stage ended with two questions which were intended to (a) summarize the particular stage and (b) bring closure to the discussion for that particular stage of life.

3. If you had to summarize the major influence your father had at this point on your life, what would you have said? 
4. What, if anything, would you have liked more of from your father or what could your father have done during your (1ife stage) to better meet your needs?

Upon completion of the questions pertaining to the four life stages, the following question was asked of the sample subjects. This question was intended to (a) bring complete closure to the entire interview process with each candidate and (b) to focus on the future of fatherhood from the perception of the subjects.

5. If you had a good friend who had just become the father of a brand new baby girl, what message would you want to share with that father?

\section{Setting for the Interviews}

The two pilot subjects and ten sample subjects selected the location which accommodated the subjects' needs. The length of each interview was approximately two and a half to three hours long.

The protection of subjects' rights and the debriefing process was based on the guidelines as provided for by the University of San Diego. All subjects were requested to sign an informed consent assuring confidentiality and anonymity of each subject (see Appendix c.)

An expedited review of the proposal was requested and approved in May 1986 from the University of San Diego Committee on Protection of Human Subjects. 


\section{Data Analysis Procedures}

Data obtained from this research project was analyzed based on (a) demographic information received from the Dissertation Interview Information Sheet (see Appendix D) and (b) the responses obtained from ten women subjects during the interviews (see Appendix E).

\section{Dissertation Interview Information Sheet}

Data collected from the Dissertation Interview Information Sheet was analyzed through the use of charts and summarized to demonstrate patterns of commonalities and differences between the ten sample subjects in relationship to:

1. the location of family life during middle childhood, early and later adolesence, and early adulthood years

2. parents' ages, occupations, and educational levels

3. birth order, number of siblings, occupations, and education levels of siblingss

4. the eight descriptive words selected to describe their fathers

5. the eight descriptive words selected to describe their mothers

\section{Interviews}

Data collected from transcribed interviews was analyzed and summarized through the following procedures:

1. Subjects' responses to each question pertaining to the developmental tasks under the life stages of middle childhood, early, and later adolescence, and early adulthood were 
condensed by this researcher into phrases and/or one or two word responses where necessary.

2. Similar and differing responses to questions pertaining to each developmental task under each life stage were summarized and put into paragraph form. These paragraphs respond to the first research question by identifying the commonalities and/or differencese of paternal parenting styles between the ten selected subjects (Chapter IV).

3. Each life stage was then analyzed and summarized in paragraph form. These paragraphs respond to the second research question by identifying behavior patterns/interactions fathers demonstrated withh their daughters during middle childhood, early and later adolesence, and early adulthood that assisted, encouraged, and motivated their daughters to become teachers and later administrators in the field of education (Chapter V).

4. Similarities were analyzed, then developed into a composite which best represents the ten women interviewed (Chapter V).

5. The final procedure responded to the following question: If you had a good friend who had just become the father of a brand new baby girl, what message would you want to share with that father? The responses from the ten subjects were quoted exactly word for word (Chapter V). 


\section{Summary}

The Dissertation Interview Information Sheet was developed to determine which pre-selected candidates would be chosen to be pilot or sample subjects. Those preselected candidates who (a) expressed a desire to participate in this case study, (b) responded to the questionnaire, and (c) circled positive descriptive adjectives regarding their fathers were selected to be sample subjects for this case study.

The survey or quantitative research study were not selected as research tools for this case study because they failed to penetrate into the true opinions and feelings of those being interviewed. The framework of the interview provided a specific form of observation, participation, and empathizing by both the interviewee and the interviewer, a process that could not be accomplished through any other method of research. The purpose of the interview was for (a) information gathering, (b) information giving, (c) expression and exploration of feelings, (d) problem solving, and (e) planning for future action (Molyneau and Lane, 1981). All interviews for this case study were taped and transcribed.

This research analyzed and summarized demographic information obtained from the Dissertation Interview Information Sheet to determine patterns of commonalities and differences between the ten sample subjects.

Responses to interview questions to all developmental tasks related to the subjects' middle childhood, early and later adolescence, and 
early adulthood years were analyzed and summarized to answer the following research questions:

1. What are the commonalities and/or differences of paternal parenting styles between the ten selected subjects?

2. What are the identifying behavior patterns/interactions the father demonstrated that assisted his daughter through the developmental tasks during the middle childhood, early and later adolescence, and early adulthood years that encouraged and motivated the woman to become a teacher and later an administrator in the field of education? 
CHAPTER IV

\section{Findings}

This research study investigated the father/daughter relationship experienced during the middle childhood, early and later adolescence and early adulthood years of ten women who currently are in a positon of principal and/or above in the San Diego County public school system. The purpose of this chapter is to:

1. summarize the findings from the ten selected subjects Dissertation Information Interview sheet through the use of charts and summary statements.

2. identify the commonalities and/or differences of paternal parenting styles between the ten selected subjects as related to the first research question.

\section{Dissertation Information Interview Sheet Findings}

Table \#1: This table exhibits the location of each subject during her middle childhood, adolescent and early adulthood years.

Seven of the ten women, subjects $\# 1, \# 2$, \#4, \#5, \#6, \#7, and \#10,

lived in the same state during their middle childhood, adolescent, and 
Table \#1

Location of Subjects During Middle Childhood, Adolescence and Early Adulthood Years

Location During

\begin{tabular}{llll} 
& Middle Childhood & Adolescence & Early Adulthood \\
\hline Subject \# 1 & California & California & California \\
\hline Subject \# 2 & New York & New York & New York \\
\hline Subject \# 3 & Minnesota & Minnesota & California \\
\hline Subject \# 4 & California & California & California \\
\hline Subject \#5 & California & California & California \\
\hline
\end{tabular}


Table \#1 (Continued)

Location of Subjects During Middle Childhood, Adolescence and Early Adulthood Years

Location During

\begin{tabular}{llll} 
& Middle Childhood & Adolescence & Early Adulthood \\
\hline Subject \#6 & California & California & California \\
\hline Subject \# & California & California & California \\
\hline Subject \# 8 & Nebraska & Nebraska & Colorado \\
\hline Subject \#9 & Kansas & Japan & Nebraska \\
\hline Subject \#10 & California & California & California \\
\hline
\end{tabular}


early adulthood years. Six of the seven lived in California while one remained in New York.

One woman, subject \#9, whose father was in the military moved from Kansas during her middle childhood years to Japan where she spent her adolescent years. Later the family moved back to the United States and settled in Nebraska where she spent her early adulthood years.

Subjects \#3 and \#8 spent their middle childhood and adolescent years in Minnesota and Nebraska respectively. Subject \#3 spent her early childhood in California while subject \#8 spent her early childhood in Colorado.

Table \#2: This table exhibits the current ages of each subject's parents, the parents' occupations, and their educational level. Subjects' fathers' ages ranged between 64 to 78 while the mothers' ages ranged between 58 to 75 .

Five of the ten subjects' fathers, \#2, \#3, \#4, \#8, and \#10, worked in blue collar occupations such as skilled laborer, building supervisor, postal clerk, farmer, and sales. Two of the subjects' fathers, \#6 and $\# 7$, were civil service workers while subjects' \#5 and \#9 fathers were a minister and military administrator respectively. One of the subject's fathers owned his own lumber company. Three of the subjects' mothers $\# 2$, \#8, and \#9 were homemakers. Two of the subjects' mothers, \#5 and \#7, were secretaries while subjects' \#4 and \#6 mothers were teachers. The remaining three mothers of subjects \#1, \#3, and \#10 were a genealogist, telephone operator, and business manager, respectively.

Five of the subjects' $\# 1, \# 3, \# 5, \# 6$, and \#10 fathers had some 
Table \#2

Subjects' Parents' Current Ages, Occupations and Education

\begin{tabular}{|c|c|c|c|c|}
\hline & Parents & Age & Occupation & Education \\
\hline \multirow[t]{2}{*}{ Subject \#1 } & Father & 65 & Owner Lumber Company & Some College \\
\hline & Mother & 58 & Genealogist & Some College \\
\hline \multirow[t]{2}{*}{ Subject \#2 } & Father & 69 & Skilled Laborer & 6th Grade \\
\hline & Mother & 64 & Homemaker & High School \\
\hline \multirow[t]{2}{*}{ Subject \#3 } & Father & 66 & Building Supervisor & 2nd yr. College \\
\hline & Mother & 65 & Phone Operator & High School \\
\hline \multirow[t]{2}{*}{ Subject \#4 } & Father & 68 & Postal Clerk & High School \\
\hline & Mother & 73 & Teacher & M.A. \\
\hline \multirow[t]{2}{*}{ Subject \#5 } & Father & 68 & Minister & 2nd yr. College \\
\hline & Mother & 67 & Secretary & Business School \\
\hline
\end{tabular}


Table \#2 (Continued)

Subjects' Parents' Current Ages, Occupations and Education

\begin{tabular}{|c|c|c|c|c|}
\hline & Parents & Age & Occupation & Education \\
\hline \multirow[t]{2}{*}{ Subject \#6 } & Father & 77 & Civil Service & H.S. Tech. Sch. \\
\hline & Mother & 75 & Teacher & B.A \\
\hline \multirow[t]{2}{*}{ Subject \#7 } & Father & 64 & Civil Service & Grade 10 \\
\hline & Mother & 64 & Secretary & High School \\
\hline \multirow[t]{2}{*}{ Subject \#8 } & Father & 71 & Farmer & 3rd yr. College \\
\hline & Mother & 69 & Homemaker & 1st yr. College \\
\hline \multirow[t]{2}{*}{ Subject \#9 } & Father & 66 & Military Administrator & B.A. \\
\hline & Mother & 66 & Homemaker & 1st yr. College \\
\hline \multirow[t]{2}{*}{ Subject \#10 } & Father & 78 & Sales & 2 yr. College \\
\hline & Mother & 74 & Manager & High School \\
\hline
\end{tabular}


college experience while only two fathers of subjects \#8 and \#9 graduated from college. One subject's \#4 father graduated from high school while two subjects', \#2 and \#7, fathers received a sixth grade and tenth grade education respectively. Four of the subjects', \#2, \#3, \#7, and \#10, mothers graduated from high school while four subjects' mothers, \#1, \#5, \#8, and \#9, had some college experience. Two of the subjects', \#4 and \#6, mothers graduated from college. One of the two, subject \#6's mother, received her M.A.

Table \#3: This table exhibits the birth order of the subjects, their siblings, current ages, occupations, and educational level.

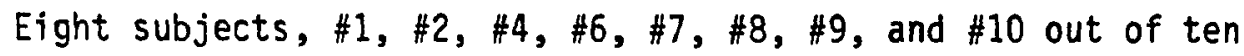
subjects, were first born. Two subjects, \#3 and \#5, were second born. This data corroborates the research studies of Astin (1969); Constantini and Craik (1972); Helson (1971); and Hennig (1976) which found that achieving women were first born. Of the subjects who were second born, subject \#3 had a sister two years older and subject \#5 had a brother two years older.

Nine of the subjects had siblings. Only one subject, \#4, was an only child. Subjects \#1 and \#9 each had one sibling, a brother. Subject \#1's brother was three years younger while subject \#9's brother was seven years younger. The other six subjects had more than one sibling, the majority of which were sisters (see chart for ages of other siblings).

Occupations of siblings who graduated from high school and/or had two years of college ranged from factory worker, shipping clerk, hair 
Table \#3

Birth Order of Subjects, Their Siblings, Current Ages, Occupations, Education

Child \#1 (Age) Child \#2 (Age) Child\#3 (Age) Child \#4 (Age) Child \#5 (Age) Occupation Education

*Subj. \#1 (31)

*Principal M.A.

Brother (28)

Self-Employed B.S.

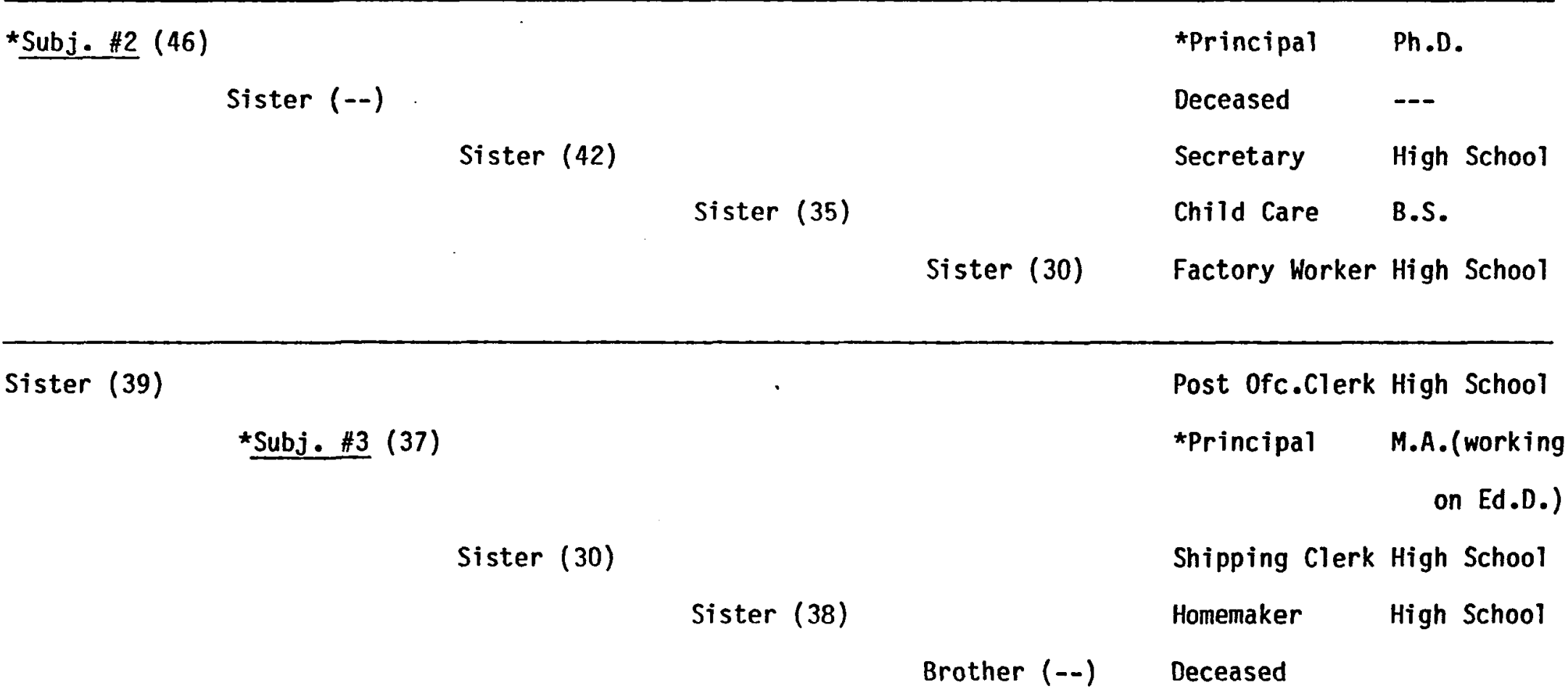




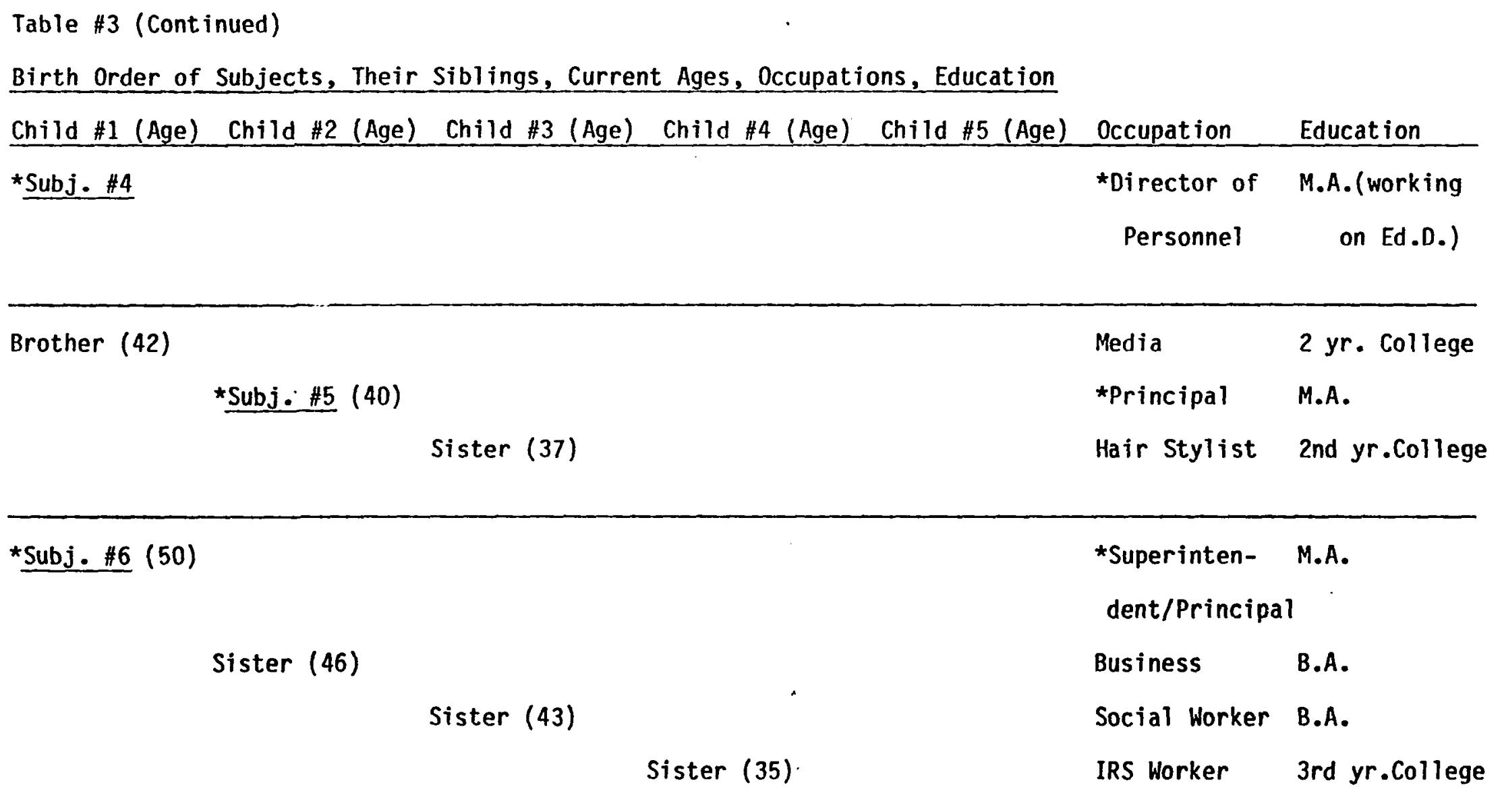


Table \#3 (Cont inued)

Birth Order of Subjects, Their Siblings, Current Ages, Occupations, Education

\begin{tabular}{|c|c|c|c|c|c|c|}
\hline Child \#1 (Age) & Child \#2 (Age) & Child \#3 (Age) & Child \#4 (Age) & Child \#5 (Age) & Occupation & Education \\
\hline \multirow[t]{5}{*}{ *Subj. \#7 (45) } & & & & & ^Principal & M.A. \\
\hline & Sister (43) & & & & Homemaker & 2nd yr.College \\
\hline & & Sister (4) & & & Teacher & M.A. \\
\hline & & & Sister (35) & & Pre-School & Junior College \\
\hline & & & & & Teacher & \\
\hline
\end{tabular}

*Subj. \#8 (47)

*Principal

M.A. (working on Ed.D)

Sister (44)

Brother (32)

College Prof. Ph.D.

Management M.A.

Consultant

Sister (29)

Newspaper Ed. B.A. 
Table \#3 (Continued)

Birth Order of Subjects, Their Siblings, Current Ages, Occupations, Education

Child \#1 (Age) Child \#2 (Age) Child \#3 (Age) Child \#4 (Age) Child \#5 (Age) Occupation Education

*Subj. \#9 (43)

*Director, M.A.

Magnet Prog.

Brother (36)

Attorney Ph.D.

*Subj. \#10 (51)

*Principal

M.A.

Brother (46)

Manufacturing High School

Sister (34)

Public

B.A.

Relations 
stylist, secretary, to post office clerk. Siblings of subjects who had graduated from college had obtained positions such as teacher, social worker, management consultant, newspaper editor, and attorney.

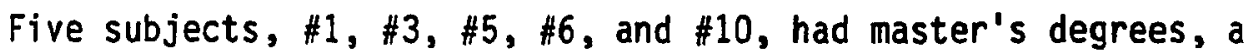
degree higher than any of their brothers or sisters. Subject \#2 had a doctorate which was also a higher degree than either of her sisters. One subject, \#7, had a master's degree as did her sister. Subjects \#8 and \#9 also had master's degrees but had siblings who had earned their doctorates. Subject \#4 was an only child.

Nine subjects had their master's degrees which surpassed their mothers' and fathers' educational levels. Subject \#4 is the only subject whose mother also had a master's degree. Table \#4: This table exhibits the descriptive adjectives subjects selected to describe their fathers.

The most frequently selected descriptor was the adjective ambitious. Honest and supportive were the second most frequently used descriptors while the words caring, humorous, and responsible were the third most frequentiy used adjectives. Affectionate, assertive, authoritarian, competitive, dominant, industrious, sincere, and understanding were selected as the fourth frequently selected descriptors. Confident, demanding, impatient, opinionated, optimistic, and trusting were the fifth most frequent1y used while the adjectives appreciative, argumentative, athletic, compassionate, considerate, mature, mentor, persistent, pessimistic, restless, sentimental, shy, silent, talkative, and warm were the least used descriptors. 
Table \#4

Descriptive Adjectives Selected by Subjects to Describe Fathers

\begin{tabular}{|c|c|c|c|c|c|c|c|c|c|}
\hline & abusive & & $\mathrm{calm}$ & & dictatorial & 1 & mature & 1 & sentimental \\
\hline 3 & affectionate & 4 & caring & & distant & 1 & mentor & 1 & shy \\
\hline & aggressive & 1 & compassionate & 3 & dominant & 2 & opinionated & 1 & silent \\
\hline 6 & ambitious & 3 & competitive & & egotistical & 2 & optimistic & 3 & sincere \\
\hline & ambivalent & 2 & confident & & emotional & & passive & & submissive \\
\hline 1 & appreciative & 1 & considerate & & forgiving & 1 & persistent & 5 & supportive \\
\hline 1 & argumentative & & cooperative & 4 & humorous & 1 & pessimistic & & tactless \\
\hline 3 & assertive & & critical & 5 & honest & & prejudiced & 1 & talkative \\
\hline 1 & athletic & & cruel & 2 & impatient & 4 & responsible & & tolerant \\
\hline 3 & authoritarian & & defensive & 3 & industrious & 1 & restless & 2 & trusting \\
\hline & boastful & 2 & demanding & & irritable & & sarcastic & 3 & understanding \\
\hline
\end{tabular}


Table \#5

Descriptive Adjectives Selected by Subjects to Describe Mothers

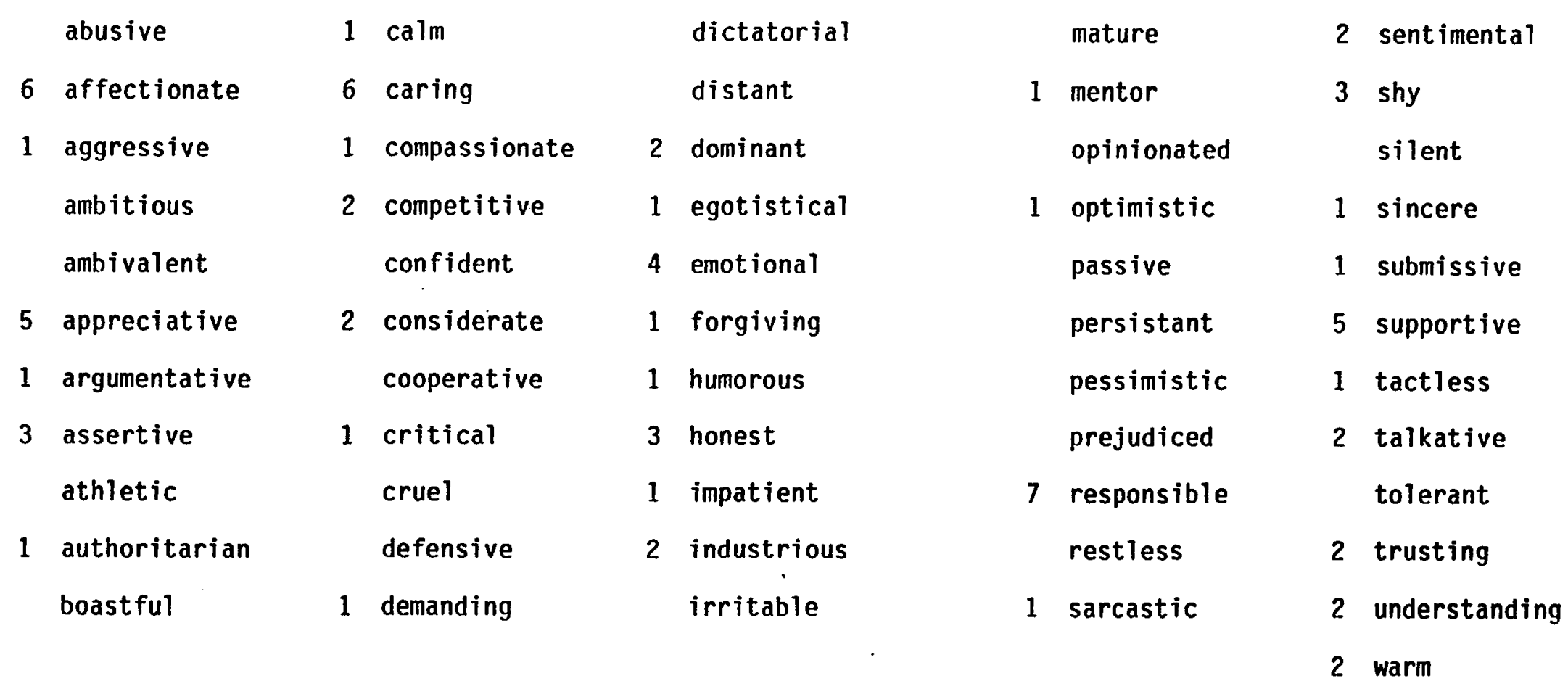


Table \#5: Table \#5 exhibits the descriptive adjectives subjects selected to describe their mothers.

The most frequently selected descriptor was the adjective responsible. Affectionate and caring were the second most frequentiy used descriptors while appreciative and supportive were the third most frequently used adjectives. Emotional was the fourth most frequently used descriptor while assertive, honest, and shy were the fifth most frequentiy used adjectives. Competitive, considerate, dominant, industrious, sentimental, talkative, trusting, understanding, and warm were the sixth frequently used descriptors. Argumentative, authoritarian, calm, compassionate, critical, demanding, egotistical, forgiving, humorous, impatient, mentor, optimistic, sarcastic, sincerity, submissive, and tactless were the least frequently used descriptors.

\section{Interview Questionnaire Findings}

First Research Question Findings

The following findings respond to the first research question by identifying the commonalities and/or differences of paternal parenting styles of the ten selected subjects during their middle childhood, early and later adolescent, and early adulthood years. 
Middle Childhood (8-12)

A. If your father were talking to his best friend about you during this life stage, between the ages of 8 and 12, what would he have said about you?

B. If you were talking to a friend at this time in your $7 \mathrm{ife}$, how would you have described your father?

Al1 women stated their fathers would have commented on how "very proud" they were of their daughters' accomplishments, expressing positive statements such as "very good and nice kid," "very cooperative," "competitive," and "a very determined student with a good sense of humor."

Fathers were described by their daughters as "intelligent," "conscientious," "hard working individuals" who "were strict but maintained a good sense of humor." One woman stated that her father was "a man of many talents who could repair anything and everything." Another women stated that since her father "was not home much due to his time in the armed forces," she was quite vulnerable to anything he said when he was home because she "wanted to please him so much." Social Cooperation

1. What do you remember about your friends at this age?

2. How did you feel about your friends?

3. Was your father aware of your friends?

4. Did your father have any influence or give you any advice 
regarding your relationships with your friends?

The majority of women had one to three very close friends who they enjoyed being with during and after school. Two women stated they enjoyed playing with boys rather than girls because they "had little in common with girls, finding them to be quite petty." One women stated that she felt insecure and jealous of her friends because she did not consider herself "to be a very popular child."

A11 of the women felt their fathers were very much aware of their friends since the daughters openty discussed their friends with their fathers and their friends spent time in their homes.

The majority of women expressed that their fathers had little or no influence on their relationships with their friends. Although some fathers listened to their daughters talk about their friends, they did not offer any advice. As stated earlier, it was assumed that the daughters would and could hold their own with their friends, be able to take a stand for one's rights and not take advantage of other people nor to be taken advantage of.

Self-Evaluation

1. How did you feel about yourself at this time in your life?

2. Was your father aware of how you felt?

3. Did anything he say contribute to the way you felt about yourself?

Although all of the women were very successful academically, the majority struggled internally with feelings of "lack of success socially." The majority of these women felt their parents, teachers, 
and peers perceived them as "goud girls and good students;" however, they often perceived themselves as being "shy, and/or self-conscious," "frustrated, naive, and innocent." Two women stated that they felt "OK" and "self-assured."

Three women commented that their fathers' awareness levels were high because they "shared with their fathers their experiences and feelings." Others felt, however, that their fathers were only "somewhat" or "not at all aware" of how they felt about themselves.

Al1 the women indicated that their fathers verbally expressed positive sentiments and praise for their daughters, but were not open with their own feelings.

\section{Skill Learning}

1. How did you feel about school at this age?

2. How did you feel about yourself in school?

3. Did your father help you in any way with your schooling at this time?

4. What importance, if any, did your father place on school? Homework?

5. What kinds of non-academic skills or talents did you learn at home? Who helped you learn these skills?

All women stated that school was a very positive experience. It was a place where they received a great deal of recognition for academic excellence which made them feel "confident," "capable," and "comfortable" in the academic setting. Several women expressed, however, that although they felt accepted within the school environment, 
they did not feel their "social life was as successful."

Five women stated that their fathers did not need to help them with their homework but expressed that if they needed help they would have been there for them. One stated that her father did not help because he did not consider himself "to be very intelligent" (he had migrated from Europe and could not read or write English).

A11 women stated that their education was a top priority to their fathers. Completion of homework was an expectation that was assumed and understood by all the daughters.

Mothers taught their daughters a variety of non-academic skills such as cooking, sewing, card games, gardening, and piano. One woman stated she learned "how to organize and use time management skills effectively." Fathers taught their daughters other activities ranging from how to play baseball, appreciation of sports, how to use basic tools to build. One woman stated that her father taught her "how to debate," how to use the library, and to carry on conversations regarding politics." Another women stated that her father taught her how "to be senstive and relate to others." Team Play

1. What kind of extra-curricular activities did you participate in?

2. Did your father actively participate or play a role in or support you in these activities?

Women stated they had participated in extra-curricular activities such as Brownies, Campfire Girls, and Girl Scouts. All of the women 
played a musical instrument; the piano was the most frequently mentioned instrument. Some of the women also took dance lessons. One sang in the church choir; one was a cheerleader while another actively participated in swimming.

Fathers supported their daughters' extra-curricular activities by listening to their daughters share with them their experiences and/or driving their daughters to and from the activities. One woman stated that her father was unable to participate "because he was in the armed forces and not home often during this life stage."

C. If you had to summarize the major influence your father had at this point on your life, what would you have said?

D. What, if anything would you have liked more of from your father or what could your father have done during your middle childhood years to better meet your needs?

A11 women stated their fathers were very supportive of them giving them the confidence to excel.

The continuous support from the father fostered confidence, pride in whatever they wanted to accomplish. Academic excellence, hard work, responsiblity for one's own actions were expectations set by all fathers. Women also stated that their fathers were "caring," "giving individuals who provided "security for them within the family unit." All women expressed that their fathers had strong beliefs in discipline and set high expectations not only for themselves but for the family. 
The majority of women stated they would have liked their fathers to have been more openly affectionate with them and demonstrate more patience toward them. The women also would have liked their fathers to have been more involved in their lives by spending more time talking and sharing in their activities outside of school.

Fathers assisted their daughters to establish and maintain a sense of mastery over their environment and to excel academically. Daughters experienced a very supportive caring relationship which enhanced their self-esteems. This allowed daughters to enter early. adolescence trusting their fathers and the guidance they were to provide through early and later adolescent life stages.

Early Adolescence (13-17)

A. If your father was talking to his best friend during this life stage, between the ages of 13 and 17 , what would he have said about you?

B. If you were talking to a good friend at this time in your life, how would you have described your father?

The majority of women stated that their fathers would still have shared their pride for their daughters' academic excellence and "initiative." One woman stated that her father would have talked a lot about the leadership roles she had assumed in school. Four fathers were 
described as being concerned about their daughters "being too interested in boys," "seeking independence too soon," "trying to grow up too fast," and "being less cooperative than in the past."

All of the women expressed they had "strict rules" to follow, were "worked too hard doing chores inside and outside," so "tightly scheduled" they were not allowed "a lot of goofing around time." Although women felt restricted by the rules they were to follow, three of three women stated they still felt the continued support from their fathers.

Physical Maturation

1. During early adolescence, one goes through many changes; how did you feel about this?

2. Was your father aware of those changes?

3. Did your father notice or make comments about your physical appearance?

4. Did your father have any influence on how you felt about your physical changes?

The women in this study reflected upon their adolescent years and the physical changes they developed. Several women referred to these years as the hardest time of their lives. The difficulties noted were feelings of "confusion," "insecurity," "concern over body development," and for one woman, "problems with my mother."

The majority of women felt that their fathers were very aware of the changes in their physical development. Only two women felt that their fathers did not notice their development. One woman commented 
that while her father appeared to be unaware of her physical changes, behavioraliy he restricted her activities during this stage. She remarked, "I suddenly wasn't allowed to do a lot of things."

Generally, fathers did not comment about their daughters' physical appearance. Many of the women couldn't remember if any remarks were ever made. Two felt that their fathers did make proud positive comments.

Fathers did not appear to influence their daughter's feelings about their physical changes. The majority of women felt that their fathers allowed them to feel comfortable about themselves and little emphasis was placed upon their physical characteristics. One woman's remark best summarizes this attitude: "he would have loved me if I was 300 pounds." Formal Operations

1. Was there any time in your family life when you talked about what was going on in the environment outside the home?

2. What importance, if any, did your father place on school? Community? Home?

3. Was there any family discussion about your career?

4. Did your father have any influence on how you thought or felt about the world and the events going on in the world during your early adolescence?

5. What rules, if any, were you asked to follow?

6. How did you feel about these rules?

7. What part did your father play in making these rules and/or enforcing them? 
Six women remembered spending time discussing events outside the home during their adolescent years, while four responded that they did not. Of the women who spent time talking with their fathers, one stated that the discussions were related to military issues, while another remembered school issues being the most prominent.

Fathers seemed to place the most importance upon school, the majority of women responded when asked about school, community, and nation. One woman remarked that church was an important thing in her home life. An equal amount of women felt that their fathers really didn't place much importance on any of these issues.

Many of the women in this study decided early in life that they would be teachers when they grew up. Many of the fathers learned early about this decision and seemed supportive of their choice. Women seemed to feel that their fathers did not affect the choice of career as much as their fathers supported whatever they wanted to do. The majority of the fathers expected their daughters to have a career, take care of themselves, and receive a higher education. Fewer women felt that career issues were never mentioned, or that their fathers assumed that they would marry after high school.

High morals and ethical behavior was mentioned by women as important values that their fathers passed on. Not many of them remembered world events being major topics of discussion but felt that their views about the world took on an ethical image based upon their fathers' influence.

One woman's comment about the rules she was expected to follow 
seems to best reflect the majority of statements made by women: "I do not remember things being rules...they were more like standards and explanations and expectations of what is right and wrong and you did what was expected of you." While some women remembered the typical household rules being maintained and chores expected, many others reported the importance of being good and doing things correctly. All women felt that the established rules were strict but appropriate for them during this life stage.

When asked whether fathers played a part in making these rules and in enforcing them, some women firmly replied, "yes," while other women felt that their mothers generally set and reinforced these rules. One woman responded that both her father and mother made them together. Emotional Development

1. As you reflect back on what your adolescence life was like for you, what particular areas were of concern? What areas of your life made you happy? Sad?

2. What part did your father play in your life regarding sex education development during early adolescence?

3. Did you choose someone to model?

4. Did your father see or admire anyone in your life or in the world who exhibited behaviors that he thought you should model?

5. Would you consider your father a model for you?

Women seemed to be most concerned about their appearance or about having friends more than other things during their early adolescent years. Social interactions with boys and concerns over being left out 
were mentioned when women reflected upon feelings of sadness. Other feelings of sadness and/or concerns included "little things with girl friends," "my family not having money to spend on a new car or a T.V.," and wanting to date.

Feelings of happiness typically centered around school. The majority of women felt very satisfied with their academic performance and achievement. One woman felt secure when she was with her family and identified this feeling as one of great happiness.

Fathers had very little to do with the sex education of their daughters. Most of the women stated that it was their mothers who held this role.

The women in this study did not recall modeling themselves after anyone in particular, nor did they remember that their fathers expected them to model after a particular person. Some felt that they might have thought about modeling themselves after a teacher, and two women thought that their fathers would have considered that they should be like their mothers.

All women unanimously believed that they would consider their fathers as models; "just as the kind of person you want to be." Membership in the Peer Group

1. How would you describe your peer group?

2. Did you have close friendships with girls? Boys?

3. How would you consider your place in your group of friends?

4. Would you at this time, in early adolescence, consider yourself to be a leader? 
5. Did you hold any leadership positions in school? Socially?

6. Did your father help or advise you in any way in making the decision to obtain a leadership position (elected office)?

7. Did he relate any of his leadership experiences to you?

The most typical peer group encountered by these women could be characterized as a group of highly motivated and goal oriented students. Women remarked that their friends were "task oriented," "responsible," "good students," "college-bound," "achievers," and "leaders." Other identifiers included "nice," "better looking than me," "fun," and "older."

Mixed responses were expressed regarding friends of the same and opposite sex. Half of the women had friendships with both boys and girls. The other half stated that they had friendships only with girls, and one stated that it was not common to have a friend who was a boy. Most women considered their position in their group of friends as "strong," "secure," "good," or as "a leader." One woman stated that she felt "kind of in the middle;" it just depended which group she was with at the time. Another woman perceived herself as "just a hanger-on."

There were a wide variety of leadership positions held by these women such as yearbook editor, president of the Latin Club, Girls' Honor Society, Scholarship Foundation, and Student Council president. Other activities included vice-president of Girls' Athletic Assocation, captain of the cheerleaders, commissioner of elections and/or holding an office in Future Farmers of America Club, or Job's Daughters. Two women did not hold any leadership positions in school due to part-time jobs. 
Only three fathers provided their daughters with advice or help in obtaining a role of leadership. One woman stated that her father helped her because "he'd been involved in politics within the community." None of the fathers were described as sharing or relating any of their leadership experiences with their daughters. Heterosexual Relationships

1. At this age, how would your describe your relationships with boys, adults, teachers, authority figures?

2. What was your father's attitude toward boys, aduits, teachers, authority figures?

The majority of women felt they had normal relationships with boys. Two women stated they did not have boyfriends at this time. Relationships with girls flourished and were numerous. All the women stated that they had very good to excellent relationships with adults as well as with their teachers. One woman mentioned that the only adult she did not get along with at this age was her mother. Adults in authority positions such as police, truant officers, and principals of schools were respected authority figures.

The majority of fathers were described as being accepting, easy going and welcoming of the boyfriends. One woman felt her father was too busy to have noticed while another stated that her father felt that she should "stay on task for school." All of the women were expected to respect adults, teachers, and authority figures. 
C. If you had to summarize the major influence your father had at this point on your life, what would you have said?

D. What, if anything, would you have liked more of from your father or what could your father have done during your early adolescence years to better meet your needs?

Most women were influenced through their fathers' acceptance of their set goals, support for all past accomplishments, and continued pride in their academic excellence. One woman concluded by stating that her father was more of a stabilizing factor because he was easy going "especially between me and my mom."

Women expressed that they wished they had received "more affection," "trust," "acceptance" from their fathers. Others stated they would have liked their fathers to have been more open in conversation about their own feelings, and the world outside their home environment. Other concerns related to more assistance with the choice of careers and with decisions related to all aspects of their lives. Two women appreciated their fathers' efforts during this life stage by commenting that "I think he gave all that was possible for him to give considering the time" and "I think he did a really good job."

Fathers assisted and allowed their daughters to have the freedom to develop as individuals with boys and girls. Conflict did not dominate the home environment due to the fact that the values of the peer groups 
were fairly balanced with the values of the father. Daughters experienced a time with their peers that was academically very task and goal oriented. The development of industry from middle childhood and group identity from early adolescence permitted the daughters to establish and develop autonomous behaviors in later adolescence.

\section{Later Adolescence (18-22)}

A. If your father were talking to his best friend about you during this life stage between the ages of 18 and 22 , what would he have said to you?

B. If you were talking to a friend at this time in your life, how would you have described your father? Or what would you have said about him?

A11 women stated that their fathers would have continued to have conveyed their support and pride in their daughters' academic excellence in school. Two women commented that although their fathers were proud of their academic accomplishments, they were "disappointed" in their choice of husbands.

Thoughts shared with friends varied from "my father continued to be 'hard working,' 'demanding,' 'reliable,' and 'helpful' to "domineering a little too much." One woman stated that "I had learned a lot of respect for him." Another woman summed it up by stating that, "he may have been narrow indeed and far too restrictive, but he was genuine. 


\section{Autonomy from Parents}

1. Were there any ways you felt dependent on your parents at this time?

2. How did you start to show your independence?

3. How did your father, if he did, encourage your dependence or independence?

By this life stage, 9 of the women had already married. Women stated that although they were "to a certain extent financially dependent on their families for college expenses, women made comments such as, "I felt connected to them but not dependent. They made darn sure I was not going to feel dependent," and "I felt very able to become independent as a result of what they had given me."

Women demonstrated their independence in a variety of ways such as "choosing my own college to attend," "living in a co-ed dorm," "making more of my own decisions the longer I stayed away from home" or "by marrying someone my parents did not want me to marry." One woman stated that when she got married and had a baby," I told my parents that I was now grown up."

The majority of fathers were described as encouraging their daughters' independence by sending them away to college. One woman stated that she "was given an allowance during my senior year in high school and could not ask for any other money from them. I had to make all of my own decisions for clothes, personal items, etc. They also had me set my own hours and choose my own college." Another woman stated that al though she was not given "much rein...they did not encourage me 
to feel like I could not manage without them."

\section{Sex Role Identity}

1. How did you feel about being female? Becoming a woman?

2. Who did you more closely identify with - in your family? Outside your family?

3. How did your father feel about you being female?

Five women stated that they had not given much thought to being female at this particular time in their lives. Others described their feelings as "I loved it," "I had no objections," or "fine." One woman commented that she did not recognize the limitations of being female "until there were times when I thought boys got to do more than me." The realization of limitations came to another woman during the selection of a career, "you were either a nurse or a teacher."

Eight women felt very strongly that they identified with their fathers. One of the eight also identified with "some of my teachers." One woman felt that "personality-wise my Dad, in terms of academics my mother and maternal grandmother." Another felt that she identified with her mother more "because my Dad was gone a lot in the service."

Responses varied to question number three. Two women feit their fathers were very proud, "I think I was very precious to him" or "he always encouraged me to do whatever I wanted to do." Other responses ranged. from "I'm not sure how he felt about it" to "children are children, boys or girls, it did not make a difference to my Dad," to "I do not think he had any special feelings about it because he had five girls and no boys." One stated that "I think he thought I was 
eventually going to be some good little wife for some nice minister." Internalized Morality

1. During adolescence, how did you make decisions?

2. Did your father have input to your decision making process?

3. How did you feel at this time about the standards that were set for you?

Statements such as the following describe how the majority of women : made decisions: "I did what I thought was right." "I did not want to disappoint my parents; they had some very clear guidelines as to what was acceptable and what was not," "I figured out what the consequences were going to be and decided if I wanted to pay that price or not," and another woman stated "I did a lot of things because it was just like me and my parents would want me to do it...just as long as it did not make waves." One woman felt that "I'd better make this decision because I did not want my Dad mad at me or perhaps it was I did not want to lose his respect...perhaps it was a combination of the two."

Three women felt their fathers had not provided input to their decisions. One of the three added "he did not like what I wanted a lot of the time." Three women responded with "I think maybe" and three responded with a definite "yes." One woman stated that her father wanted her to "do what you know in your own mind is the right thing to do."

One woman out of ten felt that the standards set for her were "fine." The other women felt that the standards were "too harsh, too rigid" and "negative" however "it's what was expected." Although one of 
the women felt the standards were "very stringent" she expressed they "were not ones that I could not deal with." Career Choice

1. What kinds of things did you do in later adolescence to help you in making a career choice?

2. When did it become clear to you that you wanted to enter educational administration?

3. What kind of input or influence did your father have, if any, on this decision?

Four women stated that since early childhood they had always wanted to be teachers. Another stated that her "high schoool counselor whom I admired a great deal thought I should be a teacher; he is probably the first one who planted the idea in my mind." Another woman stated that she "had a wonderful English teacher who helped me a great deal. I loved English too, so I decided to become an English teacher." Two women felt that the selection of a career for women at this time was very limited. According to them, a woman either became a nurse, secretary, or teacher. One of the two stated that she did not want to be a nurse because she "did not like taking care of people, so obviously I had better be a teacher... I literally became a teacher because I did not see any other options." The other woman also recognized that she did not want to be a nurse nor a secretary. "I loved school and I felt safe there so I became a teacher."

Two women shared different experiences. One said that she "looked around, and talked to a lot of my other friends who were in their majors 
and decided that I was too lazy to work that hard...that I could graduate with a teaching credential, maintain a $\mathrm{B}+$ average, without a whole lot of effort...I looked at the line of least resistance and yet something in a direction of something I wanted to do...then I did some teaching and I knew that was my direction." The other woman stated that "an education major was a tentative decision when I entered college. I took some other courses in other fields which entertained and amused me, but it seemed the longer I was there [in college] that education was the right choice."

Most of the women reached the decision to go into educational administration during either their late twenties or middle thirties with teaching experiences ranging between five and ten years. Two women further commented that she "always" knew that she "wanted to be more than a classroom teacher." Another said that she "wanted to be the person in charge." One stated that "it just happened."

Oniy one of the ten women stated that her father had a direct influence on her decision to go into educational administration. The majority of women felt that their fathers had "no direct influence" on their decision to go into administration; however, statements such as the following were added: "although he was very proud of me for reaching that decision;" "if anything, it was an indirect influence; he always thought I could do more than what I was doing, but teaching was ok because it was honorable;" "but it was very clear that I should do something to support myself;" "he thought, however, that it was an appropriate decision for me to make." One woman stated that her father 
"was a little concerned; he wanted to be sure that I got into something that I really liked, being the boss... he was worried I would not like being at the top because it was lonely at the top."

C. If you had to summarize the major influence your father had at this point in your life, what would you have said?

D. What, if anything, would you have liked more of from your father or what could your father have done better during your later adolescence to better meet your needs?

The majority of women still felt their fathers.' influence was encouragement and support. Their feelings were summarized by one woman when she stated that "I think again it is not the direct influence; it is all of his influence in my life." One stated, however, that she experienced internal conflict during this life stage because her father "wanted my goal directed toward my profession and I had just gotten married and had a child...it was a real conflict for me." Another stated that she felt "very little" influence.

Three women were satisfied that their fathers had done their best in meeting their needs during this life stage. However, the rest of the women would like to have had their fathers be "more interested in what I was doing;" "more involved in terms of affection;" "known a little bit more about what college was all about;" "more encouragement and discussion of what I was doing." 
Fathers assisted their daughters to further develop and enhance their sexual, moral, and individual identities. These fathers continued to maintain high expectations for their daughters. Daughters entered early adulthood with similar traditional background assumptions, values, and expectations for themselves.

Early Adulthood (23-34)

A. If your father were talking to his best fried about you during this life stage, from 23 to 34 , what would he have said about you?

B. If you were talking to a friend at this time in your life, how would you have described your father? Or what would you have said about him?

Accolades would have been conveyed by five fathers regarding the ir daughters' successes with academia as well as with their new family 1ife. This was expressed as "proud of all her accomplishment," "super mom, daughter, principal, really doing well, very proud and hard working." Two fathers were described as conveying only part of the above message, such as "professionally, she is doing fine; she is well recognized in her district; she is a leader, but her personal life is a mess; she has not gotten that together yet." One woman stated that her father was "somewhat incredulous" that "although he was always supportive of my administrative role, he was not real sure how I got 
into it all, and not totally clear why I enjoyed it, because he turned down administrative positions regularly."

During this 1 ife stage women described their fathers as "being very supportive, closer as they grew older," "hard working," "a loving grandparent," "he was always there when and after my husband was so seriously injured," "very hard working," "a person with many interests, very active, very self sufficient." One woman noted that during this time, her father had several heart attacks and had made some major changes "so he is a different person now than he was then. Now he is mellow and much more affectionate." Another stated that "he's getting better at talking to my mom, and he has an easier time talking with me now, too."

Marriage

1. During this period of time, did you make a decision about whether marriage would a part of your life goal?

2. In perceiving or observing your parents' marriage, how did you feel about marriage and when or whom you would marry?

3. Did your father have any influence on whether marriage would be a part of your life?

4. Do you feel you married a man who has qualities of your father? A11 women stated that getting married was a life goal. Typical comments were "I just assumed that marriage was what I would do;" "it was an unstated expectation, but it was not something that I was in any way in disagreement with;" "it was always a part of my life goal; I never doubted that I would be married and would have kids." One woman 
who is married stated that "it was not a conscious decision; it just sort of happened." Some women felt that the perfect partner for them would be someone just like their Dads.

Five out of the ten women perceived their parents' marriages as "being happy," "a good thing," "very secure and very stable," "they are good friends and very supportive of each other." The other five women expressed different thoughts such as "more sharing of ideas about the world," "more openness, more willingness to listen and to accept feelings and to discuss them."

All women assumed that they would marry and felt that their fathers influenced this life goal. Typical responses to this question were that women were expected to marry. One woman commented further when she said, "it was an accepted fact, but if I had never married, it would never have been a problem; it just happened that I did marry and I found someone I wanted to marry and that was just fine, too." One of the two women who has not yet married said her parents "keep hoping that someday I will get married."

Two women felt that their husbands did not share the same qualities as their fathers, although they thought so at the time of their marriages. Four other women felt as one woman stated: "I found out he does, but I did not think so at the time" I got married. One woman was not sure about the influence her father had on this life goal. Another woman stated that "I do not think I was looking for a father replacement or somebody to be like my father. The things I saw in my Dad were a lot of initiative and ambition, and need to be successfur, 
and I do not think I could have selected someone who did not have that need at that point in my life." One woman not yet married seeks qualities in men such as intelligence and a sense of humor, qualities she also found in her father.

\section{Childbearing}

1. How did you feel at this time about whether bearing children would be a part of your life goal?

2. In observing your parents' marriage and your upbringing, did that affect whether you wanted children or not?

Although the majority of women felt that bearing children was definitely a life goal, eight out of the ten women have biological children or step-children, and one has not yet married. One woman stated that "it was not a consideration; my daughter was an accident." Another stated that "initially I had wanted children, but my husband did not want any more because I inherited a child with the marriage."

Nine women responded with statements such as "very definitely," "yes," "probably did," "I never thought about not having children," "I think we were a child oriented family and the extended family was very child oriented...so I'm sure I assumed I would have children of my own." Only one woman stated that her parents' marriage had no affect on her decision to have children.

Work

1. How did you select your first work environment?

2. Did your father have any influence on the way you adapted to your work environment? 
3. Who do you feel you work with or relate to the best in a work environment - men or women?

4. Do you feel your relationshipo with your father helped or hindered this?

All women obtained teaching positions directly upon graduation from college. The majority were hired in the same school districts where they completed their student teaching. One woman sent applications all over the country and one selected San Diego while another needed a job close to the university where her husband was going to schoor. Nine women felt their fathers made "a tremendous impact" on them during their lives. They described their fathers as: "he always set an example of being very self disciplined, very task oriented, very strong in that you never whine, never make excuses; you do it, whatever needs to be done. You get it done and that is it;" "he helped me to have a more mellow perspective of working with people;" "he always talked about the feeling of responsibility to do a good job and those kinds of things." Another woman felt that her father helped her learn "interpersonal skills for he was very humanistic" while another stated that "I think he probably helped me learn the organizational skills and again the dedication for work." Only one woman felt that her father had no influence on the way she adapted to her work environment.

The majority of women felt they could relate to both men and women in the work environment. Two of these women made additional comments by stating that "it did not make a difference which sex I worked with just as long as they were direct and honest and straight forward in their 
relationships with me" and the other stated "I think it depends on the capability of the person." Two women felt that they worked better with men.

Nine women felt that their relationship with their fathers helped them to adjust and successfully work with others in the work environment. Comments to this effect were: (a) "because my Dad helped me to develop a level of skill and confidence and so forth that makes me feel ok about myseif," (b) "because I view them as equals; that was how I was treated and not thought of a just a housework person," and (c) "because my father exhibited those old fashioned values, I knew that there was always love and support underneath the gruffness, so the men's stoicness and traditional values do not bother me in the slightest." One woman was not sure, "I've supervised some men near retirement, and that is very difficult when you are as young as I was; for example, when I was 23 and the man was $57 . "$

\section{Lifestyle}

1. What were your future life goals at this time?

2. Did your father influence the way you live today?

The majority of women seriously considered and eventually did return to school to obtain their administrative credential, due to their desire to obtain an administrative leadership position. Two women stated that they had "a strong commitment during this life stage to be with their children." All of the women felt the influence of their fathers on the way they live today. The influence affected them in different ways such as "instilling hard work, and that if something is 
worth it, you are going to have to work for it." One father had been poor growing up. He wanted his daughter to appreciate and enjoy nice things. Two women felt that the influence was "more on a subconscious level."

C. If you had to summarize the major influence your father had at this point in your life, what would you have said?

D. What, if anything, would you have liked more of from your father or what could your father have done during your early adulthood years to better meet your needs?

In response to these questions, women made reflective comments regarding their father such as "I think he helped me to be directed and treat people fairly," "he is a person who has always seen life with the most positive point of view....always encouraging," "he always tried to set the example of being responsible, being dependable, planning ahead, planning for the future, being frugal, being conservative financially," and "still provides a tremendous amount of love, always, and support and encouragement." One woman summed it up when she stated that "he gave total support and belief in me, and that is beyond just being supportive, I think." The majority of women felt their fathers "could not have done anything more."

Only two women made comments such as "I wish he could have? understood my personal needs and try not to domineer so much" and "I wish we had more closeness than we ever had." 
Fathers provided a nurturing, caring, and supportive environment from middle childhood to early adulthood. This assistance provided the daughter with the confidence and competencies necessary to face issues, solve problems, and relate to others. Fathers provided a secure, stable bridge for their daughters to cross into future life stages.

\section{Summary}

This chapter provided the findings from the Dissertation Interview Information Sheet describing in chart form and through. summary statements the information received from the ten selected subjects. The second part of this chapter identified the commonalities and/or differences of the paternal parenting styles between the ten selected subjects during their middle childhood, early and later adolescent, and early adulthood years. 
CHAPTER V

\section{Summary of Findings}

This chapter provides summary statements of the four life stages discussed in this research study. These summaries respond to the second research question by identifying behavior patterns/interactions fathers demonstrated with their daughters during middle childhood, early and later adolescence, and early adulthood tht assisted, encouraged, and motivated their daughters to become teachers and later administrators in the field of education.

The summary of findings is followed by a composite which identifies the common themes that prevailed throughout the four life stages. The composite describes one woman called Susan who best represents the ten women interviewed for this research study.

The last section to this chapter responds to the final question asked of all ten subjects: if you had a good friend who had just become the father of an infant girl, what message would you want to share with that father? All responses to this question are quoted exactly as stated by the subjects. 


\section{Summaries of Life Stages}

\section{Summary of Middle Childhood (8 to 12 years)}

In response to questions $A$ and $B$, fathers would have conveyed to a friend that their daughters were good, nice kids, with a sense of humor. They would have also expressed how very proud they were of their daughters' determination to succeed.

Daughters would have expressed that their fathers were intelligent, hardworking men who although they were quite strict, had good senses of humor.

\section{Social Cooperation}

Women during this life stage had one to three close girl friends frequently over to their homes. Daughters openly discussed their friends with their fathers. Fathers listened, but did not provide advice.

\section{Self Evaluation}

Women felt as young girls that they were successful in all areas of academia; however, they did not perceive themselves successful in social settings outside the school. Fathers were assumed to have been aware of their daughters' successes in school as well as their difficulties in social environments. 


\section{Skill Learning}

School was a place where the women were absorbed in the art of learning, gravitating toward challenges in the world of academia. Fathers encouraged and supported their model students to study and learn. Although fathers maintained high expectations for their daughters, they remained available if and when assistance was needed.

Mothers taught their daughters cooking, sewing, and piano. Fathers taught their daughters to work with tools for gardening and building. Team Play

All women participated in scouts and other extra-curricular activities. All played a musical instrument which was most often the piano. Organized sports was not common at that time for girls. Fathers drove their daughters to and from their activities during which time events of the daughters' days were discussed.

In response to questions $C$ and $D$, the fathers' caring, giving, and supportive influence assisted their daughters to excel with confidence. Fathers provided security within the family unit where daughters could grow to assume responsibility for thier own behavior. Daughters expressed that at this age they would have liked more affection and patience. They also wanted their fathers to have been more involved with their lives, spending more time talking and sharing thoughts and ideas. 
Summary of Early Adolescence (13 to 17 years)

In response to questions $A$ and $B$, fathers would have conveyed to a friend that they were again very proud of their daughters' initiative toward academic excellence. They felt, however, that their daughters were far less cooperative at home, too interested in boys, and gro:ving up too fast by seeking independence too soon. Daughters expressed that al though the rules they had to abide by were rigid, fathers continued to provide support.

\section{Physical Maturation}

Women stated that this was the hardest time in their lives because they felt confused and insecure. Although fathers made limited comments about their daughters' physical development, they always felt accepted and loved.

\section{Formal Operations}

Communication between father and daughter regarding the world outside the home did not include national and international issues. Discussions at this time related to the school and the community at large. Career choice and/or opportunities were not discussed. Women felt influenced by their fathers' high moral and ethical behavior. Rules enforced by the fathers were expected to be followed with no questions asked. 
Emotional Development

All women were academically successful, socially accepted, and perceived by their peers and teachers "as model" teenagers. Women expressed that they were concerned about their physical appearance, social interactions with boys, and feelings of being "left out" during this life stage. Happy feelings consistentiy related to their life at school.

Some mothers provided sex education information while the fathers provided none.

When women were specifically asked whether they would model themselves after their fathers, their responses were unanimously "yes." Membership in the Peer Group

Some women had friends who were of both sexes while others just had girl friends. The common bond between these long term relationships was the desire to excel academically, to hold leadership positions in and outside the school environment, and to go to college. Women felt secure with their friends and perceived themselves as a "significant part of the group." Fathers did not provide advice regarding these relationships/friendships or on how to obtain a leadership position. Heterosexual Relationship

Women felt that they had normal relationships with boys. Relationships with adults and teachers were positive. Authority figures were to be respected. 
In response to questions $C$ and $D$, common to fathers was the acceptance of their daughters' goals and support of their accomplishments.

Daughters expressed that during this life stage they would have liked more affection, trust, and acceptance from their fathers. They stated that they wished their fathers had been more willing to share their thoughts and feelings regarding intimate subjects such as sex and world issues. Daughters also expressed that they would have appreciated more assistance with choices of careers and decisions with life goals.

\section{Summary of Later Adolescence (18 to 21)}

In response to questions $A$ and $B$, fathers would have conveyed to $a$ friend that they supported their daughters' academic accomplishments. Some fathers would have expressed disappointment in their daughters' choice of husbands. Daughters found their fathers to be hardworking, demanding, reliable, responsible, helpful, and genuine individuals.

\section{Autonomy}

Women chose to demonstrate their independence by choosing their own colleges to attend, living in co-ed dorms, or by getting married. Fathers encouraged independence by sending their daughters away to college. They accepted and trusted their daughters to examine consequences and alternatives in order to make appropriate life goal 
decisions. Although women were financially dependent on their fathers for at least part of their college education, they did not feel it was an issue nor did it make the women feel dependent. Sex Role Identity

Fathers appeared to accept their daughters as females. Women did not feel they had a conflict as to their sex-role. It only became apparent when the women started to examine career opportunities and the limitation society placed on them at that time.

Women identified with their fathers and some teachers. Internalized Morality

- Fathers taught and expected their daughters to examine alternatives and the consequences to alternatives before making decisions. Women stated that although some of the decisions were not correct, their fathers still were very accepting of them.

Standards were expected to be followed, not questioned. Career Choice

Four women wanted to be teachers when they were young children. Two women stated that their high school English teacher and counselor respectively influenced their decisions to go into teaching. Four women chose teaching because they saw only three choices for careers: nursing, teaching, and secretarial work. One of the four chose teaching because it was "the path of least resistence."

Women taught five to ten years before thinking about and/or seeking an administrative leadership position. Fathers had no direct influence 
on their daughters' desires to obtain an administrative position at this time.

In response to questions $C$ and $D$, women felt continued support and encouragement from their fathers.

Three out of ten women were satisfied with what their fathers had provided them during this life stage. The other women expressed that they would have liked their fathers to have exhibited more interest and encouragement in their daily lives. They also expressed that they would have liked their fathers to have been more knowledgable regarding all aspects of college life.

Summary of Early Adulthood (22 to 34 years)

In response to questions $A$ and $B$, fathers would have conveyed to a friend that they were proud of and enjoyed listening to their daughters' academic and professional accomplishments. Fathers would have expressed their delight with their new grandchildren for those women who had married. Some fathers felt that their daughters, although professionally stable, did not exhibit stability in their personal lives and expressed disappointment.

Fathers were described as being very active, self-sufficient individuals who always remained supportive of their daughters' goals. 
Marriage

A11 women stated that marriage was a life goal. Fathers influenced the feelings of marriage because it was an expectation. Nine women got married, one of whom is now divorced. The tenth woman has not yet married.

Some women discovered later in marriage that their husbands had qualities similar to their fathers in the early stages of their marriages, but discovered later that those qualities were not the same at all.

Childbearing

Childbearing was an expected life goal. In reality, only six women had their own biological children and of the six, five were planned. Two of the remaining women have step-children; two had no children. Work

Fathers were highly influential, impacting their daughters' confidence to succeed, their rigorous work ethic, and the feeling of being OK. Women were task oriented, responsible, and committed to their work. Knowledge of organizational and interpersonal skills was felt to be critical to adjusting and enhancing the work environment. Gender of co-workers, peers, and/or subordinates was not an issue. Women respected and enjoyed working with those who were straight forward, direct, and honest.

Lifestyle

Women felt they wanted to seek an administrative leadership position after teaching for approximately five to ten years. Women 
stated that al though their fathers did not directly influence their decisions to go into administration, the values, support, and encouragement they received from their fathers did impact their lives.

All women felt that their fathers influenced the way they lived during this life stage because of the high expectations set for them during their upbringing. The majority of the women had started to work on their administrative credentials during this life stage to seek an administrative leadership position.

In response to questions $C$ and $D$, the fathers' conservative influence directed the women toward particular goals, planning, and saving for the future. They set examples of fair play, dependability, and responsibility toward others as well as toward oneself. The majority of women expressed that they wanted more understanding of their personal needs and closer relationships with their fathers.

\section{Composite}

This composite depicts the common themes prevalent in the four life stages.

Susan was born in 1944 to white working middle class parents. She was the first born of three girls. She spent her middle childhood, early and later adolescence, and early adulthood years growing up and attending schools in southern California. Susan's mother and father 
graduated from high school and attended two years of college. Her father was a blue collar worker while her mother was a homemaker and secretary. Both are now retired. The second oldest sister is now 42 and works as a clerk in a local business. Her youngest sister is 40 and is a receptionist in a doctor's office. Susan is now 44 and is currently an elementary school principal in the San Diego County public school system.

Susan selected the following adjectives to describe her father: ambitious, humorous, honest, responsible, and supportive. She selected the following adjectives to describe her mother: affectionate, appreciative, caring, emotional, responsible, and supportive.

Middle Childhood (8-12)

Susan had two close girl friends who together went through elementary, junior high, and high school. Their constant companionship resulted in weekly if not daily visits to each other's homes. Susan related her experiences, ideas, thoughts regarding her friends to her father who in turn 7 istened to her but did not give any advice.

Susan felt successful in school where she did extremely well in all academic subjects. She did not feel, however, that her social life in school matched her academic success. She assumed her father was aware of her feeling insecure in social situations; no conversations regarding Susan's insecurities were ever held.

At school, Susan was a model student where she found many 
challenges in her daily life. Although Susan's father had high expectations for her, she knew that he would always be there if she needed assistance with her homework. At home, Susan was taught by her mother how to cook, sew, and play the piano. Her father, when he had time, taught Susan how to use gardening and building tools.

Susan participated in a Brownie Troop along with her two girl

friends. Other extra-curricular activities related to piano lessons and playing baseball with her friends in the neighborhood for there were no organized sports for girls during this time. Her father drove Susan to and from piano lessons during which time she conversed with her father about the events of her day.

Reflections

Susan felt that her father would have described her as being a basically good kid with a very good sense of humor. She would have described her father as a very hardworking, intelligent man who was very strict but who was able to enjoy a good laugh once in a while.

Susan's father's supportive, giving, and caring attitude toward her gave her the confidence to accept the challenges during this life stage. She would have liked more demonstration of affection, patience, and time for sharing of ideas and thoughts.

\section{Early Adolescence (13-17)}

Early adolescence was a time in Susan's life that was stressful and laden with feelings of insecurity and confusion about her physical 
development and the world around her. Although Susan's father rarely made comments about her physical changes, she still knew that her father loved her and accepted her.

Conversations with her father related to his moral and ethical thoughts regarding school, the community at large, and rules she was expected to follow. Career choices/opportunities and issues regarding national and international affairs were not discussed.

Susan continued to feel successful academically but not socially. She knew, however, that her friends and teachers perceived her to be a model student and that she was accepted in all social settings in and outsside of the school environment. Her education regarding sex was taught to her only by her mother. However, she identified with her father.

Susan's friends were boys and girls who were conscientious, goal oriented students holding leadership positions in school and aspiring to attend college upon graduation from high school. Susan felt secure with her long term relationships and was pleased about her own attainment of positions in leadership. Her father enjoyed Susan's enthusiasm for her friendships and success in school; however, he did not provide advise.

Susan had typical relationships with boys during this life stage. Her relationships with other adults, teachers, and authority figures were positive and ones of respect.

\section{Reflections}

Susan's father would have conveyed to a good friend that he was very proud of his daughter's ability to excel academically, but that she 
was becoming more argumentative with her mother and less cooperative around the house. He also would have expressed his concern about Susan's interest in boys, and the desire to want more and more independence. Susan felt the rules her father had enforced during this life stage were too strict; however, she made a conscious decision to follow them because she knew she would have to pay the consequences.

Although Susan felt continued support from her father regarding her goals, she would have wanted more trust, affection, and acceptance from her father. She also wished that discussions with her father exposed more of his feelings about sex, boys, world issues, and career opportunities.

\section{Later Adolescence $(18-21)$}

Some of the ways Susan demonstrated her independence was to (a) select the college she would attend for the next four years, (b) live in a co-ed dorm, and (c) drink at parties. A large portion of Susan's college education was paid for by her parents; other expenses such as books were paid with scholarship monies received by Susan. Personal expenses were paid with money Susan had earned from jobs during high school and college summer breaks.

Sex role conflict and society's limitations on women did not become obvious to Susan until she started to examine career opportunities. Although she identified with her father in many ways, she felt the only career opportunities she had were teaching, nursing, or secretarial 
work.

Susan's father stated that she should and was expected to follow all rules. He taught her that before making any decisions she should review all the alternatives and consequences associated with that decision. Susan felt that her father would remain supportive of her despite the fact that some decisions were inappropriate.

Ever since Susan was a young child, she had always wanted to be a teacher. Her major in college was elementary education and upon graduation she obtained a teaching credential. She taught elementary school for eight years before seeking an administrative leadership position. Her father had no direct influence on her decision to obtain a higher position in the field of education.

\section{Reflections}

Susan felt her father would have expressed to a friend his support for his daughter's academic acoomplishments but concern about her possible selection of a particular man to marry. Her father still remained supportive and encouraged her to reach her life goals. Susan would have appreciated more input regarding college life; however, for the most part she was quite satisfied with what her father had provided for her during this life stage.

\section{Early Adulthood (22-34)}

Susan married at the age of twenty-three and later had two children. Her husband exhibited some of the same qualities found in her 
father. Getting married and having children, Susan felt, was influenced in part by her father's expectations.

Susan was a very committed, task oriented individual who attributed her confidence and ability to succeed at work as well as at home to the values her father imparted during her formative years. She was able to deal with organizational responsibilities and interpersonal relationships, enjoying the opportunity to work with men and women who were honest, direct, and respectful.

Susan taught for ten years during which time she had decided to obtain an administrative leadership position. In order to perpare, she returned to college to obtain her administrative credential. Susan felt that her father had made a very deep impression on her life style and future goals.

Reflections

Susan's father's influence helped her to pursue her life goals by planning, saving, and setting her expectations for the future. Her father's acceptance of responsibility, dependability, and fair play toward her impacted how Susan accepted herself, family, and co-workers. The only wish she had during this life stage was to have had a closer feeling relationship with her father.

\section{Information for New Fathers}

The last section of Chapter $V$ contains statements made by the ten subjects in response to the following question: If you had a good friend 
who had just become the father of an infant girl, what message would you want to share with the father?

Love the child, give her all the wisdom you can and be supportive, help them make their own decisions, let them make their own decisions, but then support them once they do, even if you do not agree with them.

The sky's the limit, love her, nurture her, and encourage her to explore.

Act like a mother, which fathers do a lot more these days which means to me to do all the things: you feed them, and you change the diapers, and you take them places and you talk to them and you pick them up, and all those mothery things.

I would say you set no limits on that young lady, let her develop, let her experience, and when I say set no limits, I certainly do not mean to say no discipline, because I do believe in discipline, but as far as goals and that sort of thing, and certainly I feel that dad should be an active participant in the entire childrearing process, that it is a participatory activity and everyone needs to be involved, get to know your children, talk to them, cry with them when they are unhappy; laugh with them when they are happy; glory with them in their exploits and it is not easy; sometimes frustrations are beyond compare, but it is worth it. 
To love her, and be supportive, and give her some advise about men, and also tell her to be tolerant of her mother.

I think to be understanding, open, and supportive, and to set some goals and guidelines, but to allow some parameters that are somewhat flexible.

A father should raise his daughter to believe she can do anything she wants to do, but she doesn't have to; it is OK to be a mother and stay home but to help her develop her confidence and exposure so that the focus of career choices is not too narrow; give her a chance to see what is going on. I think one reason I did what I did, was that I never saw any woman do anything but teach or be a nurse. That was all I had ever seen -- so just expose them and do not put pressure on them.

Give her lots of love, lots of structure early and teach her how to make choices and allow her to do that and lots of hugs and lots of physcial staff. Help her to do lots of exploring. Do everything with her that you would do with a boy.

I would want him to know how valuable affection, warmth, gentleness, acceptance and listening, being non-judgmental means to a daughter. And that it enhances his manhood and his masculinity in the eyes of a daughter; it does, I think, of sons too, but just in a 
father-daughter relationship I think it is the basis of your own being and your own sexuality as an adult, your relationships, being able to relate to everybody. 


\section{Chapter VI}

\section{Conclusions and Recommendations}

This final chapter includes two sections. The first section contains conclusions of this study and the second section contains recommendations for the advancement of studies related to the impact and influence of the father in the family unit, the father/daughter relationship, and the coordination and collaborative efforts of all disciplines to share their findings about fathering with social agencies and educational institutions.

\section{Conclusions}

\section{Dissertation Interview Information Sheet}

The majority of successful women who hold Ph.D.'s, or are political leaders, medical doctors, mathematicians, or executives in large companies have similar background characteristics (Astin, 1969; Constantini and Craik, 1972; Cartwright, 1972; Helson, 1971; and Hennig, 1976).

1. Subjects were found to be foreign born.

2. Subjects had one or both parents born and raised in a foreign country. 
3. Subjects were from high socioeconomic.

4. Subjects had one or both parents with high occupational and/or educational status.

*5. Subjects were either the oldest or the only child.

6. Subjects did not have any brothers (Barnett, 1978).

The ten subjects in this study did not have the same background characteristics as the women in the above mentioned studies. Of the ten women studied:

1. A11 subjects were born in the United States.

2. One of the ten subjects had immigrant parents.

3. None of the subjects were from high socioeconomic levels.

4. One of the ten subject's father had graduated from college; two of the ten subjects' mothers had graduated from college, one later obtaining a master's degree.

*5. Nine of the ten subjects were the oldest child in the family, one was an only child.

6. Nine of the ten subjects had siblings, six of the ten subjects had brothers, seven of the ten subjects had sisters.

of the above characteristics discussed, only one characteristic (number 5 ) is common to the majority of subjects found in all studies.

The majority of the women in this study have the following common background characteristics among themselves.

1. Subjects lived in the same town and state during their middle childhood, early and later adolescence, and early adulthood. 
2. Subjects came from low middle to middle class families.

3. Subjects had fathers who were blue collar workers.

4. Subjects had fathers whose educational level did not go beyond high school.

5. Subjects had mothers who were homemakers or secretaries.

6. Subjects had mothers whose educational level did not go beyond first year of college.

7. Subjects were first born.

8. Subjects had siblings, the majority of which were sisters.

In conclusion, the background characteristics of women in this study did not align themselves with the background characteristics of the majority of women found in the research studies of Astin (1969), Constantini and Craik (1972), Cartwright (1972), Helson (1971), and Hennig (1976) with one exception. The background characteristic common to all studies was that the majority of women were first born which suggests that there is a correlation between being first born and the dynamics of the father/daughter relationship.

Descriptive adjectives used by daughters in this study to describe their fathers were the same adjectives used by women in other studies. Throughout the literature, two adjectives most frequently used to describe fathers were supportive and honest. Only five of the ten subjects in this study used the same adjectives when asked to circle eight adjectives that best descibed their fathers. It should be noted, however, that these descriptors were frequently used during subject interviews. It is therefore concluded that although the words "honest" 
and "supportive" were not selected by the majority of women in this study on the Dissertation Interview Information Sheet, subjects consistently felt and stated during their interviews that throughout their middle childhood, early and later adolescent and early adulthood years, their fathers were definitely supportive and demonstrated honesty at all times.

\section{Interview Questionnaire}

Middle Childhood (8 to 12 years)

The following paternal parenting styles were demonstrated and found to be common among the majority of daughters during the middle childhood life stage.

1. Fathers listened to their daughters.

2. Fathers had high expectations for their daughters.

3. Fathers were available to help and assist when needed.

4. Fathers participated in their daughters' activities.

5. Fathers provided a sense of security to assist the daughter to assume responsibility for her own behavior: both successes and failures.

6. Fathers gave much praise for all accomplishments.

The identified behavior patterns/interactions fathers demonstrated assisted their daughters to work through the developmental tasks of 
social cooperation, self-evaluation, skill learning, and team play of this life stage. The literature clearly states that fathers who set high standards, provided support and constructive criticism, and assisted their daughters to learn a variety of skills, developed in their daughters a strong sense of industry. In turn, this provides a firm foundation toward building and working through the developmental tasks found in early and later adolescence. The women in this study confirm what was stated in the review of the literature.

$$
\text { Early Adolescence (13 to } 17 \text { years) }
$$

The following paternal parenting styles were demonstrated and found to be common among the majority of daughters during the early adolescent years.

1. Fathers helped daughters to feel accepting of themselves physically and emotionally by accepting their daughters as special human beings.

2. Fathers continued to have high academic and behavioral expectations.

3. Fathers were ethical and morà individuals whose modeling influenced their daughters' behaviors, desire for academic success, and respect toward authority figures.

4. Fathers did not provide advice regarding daughters' life goals and/or friendships but continued to listen.

5. Fathers did not discuss the dynamics and facets of national and 
international world issues.

6. Fathers provided guidance in order to help daughters develop independent skills.

Fathers continued to demonstrate respect toward their daughters' personhood. The expectations set in conjunction with the caring, guidance, and modeling provided these subjects with coping skills necessary to deal with personal and professional successes and/or failures in later life stages. Fathers were not frightened of their daughters' sexual or emotional development.

The early adolescent life stage is a time when fathers start to investigate and discuss with their daughters the political, economic, and social realities of the adult world (Douvan, 1963; Fields, 1983; and Rivers, 1979). The majority of fathers in this study, however, did not explore with their daughters during early adolescence, later adolescence, or early adulthood these aspects of national and international issues. Their lack of interest or awareness can be attributed to the fact that the fathers in this study had limited educational and life experiences. The limited educational experiences and traditional background assumptions of the fathers in turn reduced their daughters' exposure and awareness of the dynamics of world issues.

Subjects in this study absorbed the majority of their parents' values which according to the literature reduces major on-going confrontations between parents' values and the adolescent's peer group values.

In conclusion, it can be stated that there were limitations on the 
subjects' awareness levels regarding the dynamics of particular segments and aspects of our society and the world. This can be attributed to the subjects' fathers, due, not necessarily to a lack of intelligence, but to (a) a lack of knowledge as to where to obtain resources to find out information regarding the political and economic nature of society and of the world and/or (b) lack of awareness as to the importance and the impact that knowledge has on one's ability to enhance, participate in, and manipulate one's environment to one's advantage.

Fathers provided constant and consistent encouragement, caring guidance, and emotionally supportive attitudes toward their daughters. Subjects were thus able to further develop and maintain a strong sense of individual identity and at the same time feel connected with or apart from their own peer groups. The identified behavior patterns/interactions fathers demonstrated permitted the subjects in this study, according to the literature, to work through the developmental tasks of physical maturation, formal operations, emotional development, heterosexual relationships, and psychosocial crisis of this life stage.

\section{Later Adolescence (18 to 21 years)}

The following paternal parenting styles were demonstrated and found to be common among the majority of women during this later adolescent life state.

1. Fathers encouraged independence by accepting their daughters' 
decisions and choice of college.

2. Fathers trusted daughters to examine their alternatives and consequences to appropriate and inappropriate behaviors.

3. Fathers continued to provide emotional and financial support while daughters were in college.

4. Fathers did not label their daughters as incapable of taking care and/or providing for themselves just because they were female.

Women in Hennig's (1976) study felt that during adolescence the most important source of support and confirmation of their developing self-concepts was what they received from their fathers. Hennig (1976) found that "fathers placed the highest emphasis on their daughters" developing skills and abilities rather than on a socially defined sex role or behavioral style" (p. 127).

Fathers did not reject their daughters' femininity, but did reject the role definition of femininity (Hennig, 1976). Daughters:

accepted feminity and its traditional objective of marriage and motherhood on their own terms. They determined they would go to college, begin a career and marry later... they rejected their mothers' traditional views and they held firm to their own objectives, relying on their fathers' support and their own inner convictions (p. 131-132).

A11 women in this study felt continued emotional support and encouragement from their fathers regarding their academic achievement and decision to go to college. Nine of the subjects had selected to 
major in education by the time they entered college. Four of the nine made their decision to pursue teaching during their early childhood years while two made their decisions in high school. Two subjects saw only three career opportunities for women: nursing, secretarial work, and teaching. They did not want to be secretaries or nurses; therefore, the only option left was to became a teacher. Another chose teaching because "it was the path of least resistance." One of the ten women in this study "looked around" and asked questions of her friends who were in other majors before confirming her decision to become a teacher. Fathers accepted and supported the traditional occupational role models for their daughters.

By later adolescence the women in this study had (a) already selected a mate whom they would marry during the early adulthood stage of life, or (b) already married by the age of 21 . For a few women there were not only inner conflicts between the desire to pursue one's goals and the expected role(s) placed on women in our society, but conflict with their fathers, who did not like their daughters' choice of mates. In conclusion, the women in this study differ significantly from the women Hennig (1976) studied during this life stage. In this study, neither father nor daughter rejected the traditional role definition of femininity as they had done in Hennig's (1976) study. Although fathers appreciated, encouraged, and supported their daughters' academic achievement, they still accepted and supported society's traditional values and expectations of women. 
The traditional values and background assumptions of the fathers, however, did not inhibit or restrict the ability of the women in this study to establish their individual identity. According to the literature, the identified behavior patterns/interactions fathers demonstrated assisted their daughters to successfully work through the developmental tasks of autonomy, sex-role identity, internalized morality, choice of career and psychosocial crisis of this life stage.

\section{Early Adulthood (22 to 34 years)}

The following paternal parenting styles were demonstrated and found to be common among the majority of women during the early adulthood life stage.

1. Fathers were traditionalists and therefore expected their daughters to marry and have children.

2. Fathers influenced and impacted their daughters' confidence to succeed.

3. Fathers influenced and impacted their daughters' maintenance of a rigorous work ethic.

4. Fathers influenced and impacted their daughters' feelings of being OK.

5. Fathers enjoyed their work as did their daughters.

By the end of this life stage (a) nine of the ten women in this study had married, (b) eight of the ten women had at least one child, and (c) all women had teaching experience of at least 10 to 14 years. 
During this life stage, the majority of women had started to work on their administrative credentials with hopes of obtaining an administrative leadership position in the field of education. Although all women made their own decisions to go into administrative leadership positions, they clearly indicated that their experiences with their fathers, their support and encouragement received from early childhood to this stage influenced, impacted, and motivated them to fulfill their aspirations of becoming a principal and/or superintendent of schools.

In conclusion, this study as well as studies by Cartwright (1970), Helson (1971), and Hennig (1976) indicate that women maintained close and very supportive relationships with their fathers during the early adulthood life stage. The identified behavior patterns/interactions fathers demonstrated during this life stage assisted these women to successfully work through the development tasks of marriage, childbearing, work, development of a lifestyle and the psychosocial crisis of the early adulthood years.

The following three points describe differences among paternal parenting styles:

1. One father was in the armed forces and was not home during much of his daughter's middle childhood years.

2. One father did not help his daughter with her homework because he did not consider himself "to be very intelligent."

3. Three fathers provided their daughters with advice with obtaining a leadership role in high school. 
This chapter has integrated the data collected for this case study by responding to two research questions posed in Chapter I:

1. What are the commonalities and/or differences of paternal parenting styles between the ten selected subjects?

2. What are the identifying behavior patterns/interactions the father demonstrated that assisted his daughter with and through the developmental tasks and psychosocial crisis during her middle childhood, early and later adolescence, and early adulthood years that encouraged and motivated the woman to become a teacher and later an administrative leader in the field of education?

\section{First Research Question}

The paternal parenting styles demonstrated and found to be common and different among the majority fathers of during their daughters' middle childhood, early and later adolescence, and early adulthood years are discussed in this chapter. It was found that there were more commonalities among the fathers' behavior patterns and interactions with their daughters than there were differences.

The literature suggests that fathers who demonstrate behaviors as exhibited by these fathers toward and with their daughters produce children, adolescents, and young adults who are confident, competent, and capable. These subjects indicated that their father's teachings, behaviors, and interactions with them influenced and impacted positively their personal and professional lives. Second Research Question

Fathers demonstrated specific behaviors that continuously validated 
their daughters' existence. They treated their daughters with respect and trusted in their ability to develop competencies necessary to become independent and successful. Fathers also assisted their daughters to develop a positive self-esteem, confidence to deal and cope with success and failures, and an appreciation for one's personal and professional skills and abilities. They continuously demonstrated and provided an emotionally supportive, caring relationship with their daughters from middle childhood through adolescence to early adulthood. These behaviors assisted and motivated their daughters to successfully work through the developmental tasks and psychosocial crisis of each life stage.

It was found that four subjects selected to become teachers during early childhood. Two subjects made their decision during early adolescence. Two subjects selected teaching because they did not want to become a nurse or a secretary. One subject selected to investigate other careers while in college before making her final decision to become a teacher. One subject chose teaching because it was "the path of least resistance." The decision to become a teacher and later an educational administrative leader was a decision that was made voluntarily by all subjects. All fathers respected and supported these decisions.

Whenever a researcher explores a problem, the answers often lead to more questions. The data obtained from the Interview Information Sheet and the responses found in the Interview Guide as well as the researcher's experiences in conducting the study suggested many areas 
for future research which will be discussed in the next section.

\section{Recommendations For Future Research}

The mother's role and influence in the family system has been well documented and researched. However, research studies have just started to investigate the dynamics of the father's influence and impact on the family system. "The changing roles of men and women, the importance of the father in child development, the importance of parenting to marital satisfaction, and the need for support systems for young families" (Jones, 1985, p. 94) are a few reasons for studying and researching the importance of fathers and fathering. Weaknesses found in the literature suggest that research needs to include studies related to:

1. the development of an evolving conceptualization of the nature and significance of fathering

2. fathers who have unusual or difficult children, marital, or living arrangement situations

3. the historical and cultural forces that shape fatherhood

4. longitudinal studies of fathers using larger heterogenous socio-economic representative samples

5. paternal attitudes and behaviors in the context of observing and examining entire family systems

6. the impact of child characteristics on paternal attitudes and behaviors

7. single father parenting 
8. the historical and cultural forces that shape fatherhood (Bradley, 1985).

The literature of the 1980 's has produced a renewed interest in the paternal interest on the dynamics of the family. Six critical factors discussed in Chapter II define and provide reasons for this interest. Books, newspaper and magazine articles about fathering are being written about father/son and father/daughter relationships whereas before 1980 this topic was usually relegated to a single chapter in a book about family life. This new literature demonstrates that the modern father of today has a desire to actively participate in the development of the socialization process of his children. As a result, of this research project, further research pertaining to paternal parenting should also include the following points:

1. the importance of the father within the family unit

2. the importance of the father's role in a daughter's development and the impact of his influence on her in a healthy family unit versus life in a dysfunctional family unit

3. the importance of paternal parenting with respect to a daughter's :

a. choice of spouse

b. marital satisfaction

c. child rearing practices

d. career choices

Further recommendations are that:

1. this study be extended to include the women's personal and 
professional and professional lives past early adulthood on into middle and later aduithood life stages.

2. the same questions posed in this case study be adapted to a survey thus reaching a larger population.

3. all disciplines coordinate and collaborate their research findings and share that knowledge among social agencies and educational institutions.

4. all disciplines investigate what and how the undergraduate, graduate, graduate and post-graduate schools of education are educating their teachers and administrative leaders to the importance of the father within the family system.

5. all disciplines investigate what and how the schools of psychology, sociology, and medicine educate psychologists, social workers, and family doctors to the importance of the father within the family system.

6. all disciplines investigate what social agencies are doing to enhance and encourage more participation of the paternal role within the family unit.

7. educators investigate what the elementary and secondary educational systems do to include the father in teacher child/student conferences, PTA, and School Site Council Meetings.

8. educators investigate the awareness level of school site administrative leaders as to their role in conferencing with fathers. 
9. support systems/groups for new fathers and families in crisis to include educators, sociologists, psychologists, pediatricians, attorneys who deal with domestic crises and judges who preside over domestic courts.

\section{Summary}

As principal of an elementary school, I spend a great deal of my time in conference with parents. These conferences have provided further evidence to this researcher that fathers are indeed confused and/or in conflict between demonstrating their masculinity and/or realizing that they are capable of demonstrating the compassionate or maternal side of their personhood. This researcher, therefore, concluded the interview with each subject by asking the question: If you had a good friend who had just become the father of an infant daughter, what message would you want to share with that father? The following underlined points were then compiled from the thoughts expressed by the ten subjects in response to the above question. This researcher has made additional comments regarding each point for purposes of clarification.

1. Be supportive: provide positive reinforcement, praise, constructive criticism.

2. Talk to her: teach her how to share feelings, solve prublems, and discuss current affairs.

3. Love her: express it verbally and with hugs. 
4. Encourage her: provide help, hope to build her confidence.

5. Nurture her: be empathetic and caring.

6. Encourage her to explore: give her an opportunity to participate in what life has to offer.

7. Cry with her: share happy and sad times.

8. Let her make her own decisions: teach her that there are alternatives to decisions and consequences that accompany each decision.

9. Let her develop: allow her to experience all that she can.

10. Give her some advice about men: teach her how to deal with men.

11. Be understanding: listen, ask questions, and tell her your perception of the decision or problem.

12. Be open in communicating your feelings: share how you feel about what is going on in your environment.

13. Set some goals and guidelines, remain flexible: all children need guidelines while at the same time meeting individual needs.

14. Do with her what you would do with a boy: do not set limits because you have a female child.

15. Help her to believe in herself, that anything and everything is possible: believe in and have confidence in her ability to succeed.

16. Be affectionate, warm, and gentle: demonstrate your affection, warmth, and gentleness.

17. Teach her how to make decisions and make choices: show her that 
choices are available and there are consequences with each decision made.

18. Listen and be non-judgemental: ask questions for clarification, respect your daugher's personhood.

Just as there are developmental tasks and psychosocial crisis to explore and conquer in each life stage, so too are there developmental challenges or crises to be explored and conquered in fatherhood. New fathers, therefore, should be made aware of and be taught skills for working with the following developmental challenges. The knowledge and the ability to successfully work through these tasks will provide for a healthy family unit which in turn will enhance the father/daughter relationship. Jones (1985) suggests that assumption of the fathering role helps a man come to terms with his repressed maternal feelings as well as reviving a man's memory of the relationship he had with his own father.

1. New fathers need to learn how to reconcile conflicting conceptions of the fathering role.

2. New fathers need to learn how to cope and deal with the new pressures made upon a new father.

3. New fathers need to learn the essentials of child care.

4. New fathers need to learn new regimens that are most healthful for the new family.

5. New fathers need to learn how to encourage the child's full development.

6. New fathers need to learn how to maintain a mutually satisfying 
companionship with their wives and daughters.

7. New fathers need to learn how to balance earning power between husband and wife.

8. New fathers need to learn how to maintain a satisfying sense of self as a man.

9. New fathers need to learn how to represent the family within the wider community.

It is imperative that administrative educational leaders remain aware of the complexities and dynamics of interpersonal relationships within the family unit. We indeed have a responsiblity to learn all there is to learn about parenting from the field of education as well as from the fields of psychology, sociology, and medicine in order to provide, assist, and enhance the healthy family unit. 


\section{REFERENCES}

Aberle, D. F., \& Naegele, K. D. (1952). Middle-class fathers' occupational role and attitudes toward children. American Journal of Orthopsychiatry, 22, 366-378.

Adams, K. A., \& Davis, L. V. (1978). The father's role and the child's development. (Report No. CG 013 808). Ontario, Canada: Annual Convention of the American Psychology Association. (ERIC Document Reproduction Service No. ED 177 386).

Adkison, J. A. (1981, Fall). Women in school administration: a review of the research. Review of Educational Research, .51, (3), 311-343. Adkison, J. A., \& Bailey, J. D. (1981, February). Increasing women's participation in educational administration. Education Digest 46 , 10-13.

Andre, R., \& Edwards, M. I. (1979). Training women for administration. In M. C. Berry (Ed.), Women in higher education, pp. 12-18. Washington, D. C. : The National Association for Deans.

Angrist, S. S., \& Almquist, E. M. (1975). Careers and contingencies. New York: Dunellen.

Antonucci, T. (1980). The need for female role models in education. In S. K. Biklen \& M. B. Brannigan (Eds.), Women and educational leadership (pp. 185-196). Massachusetts: D. C. Heath. Appleton, W. S. (1981). Fathers and daughters. New York: Doubleday. Astin, H. S. (1969). The woman doctorate in America. New York: Russell Sage Foundation. 
Bardwick, J. M. (1971). Psychology of women; a study of bio-cuitural conflict. New York: Harper and Row.

Baurind, D., \& Black, A. (1967). Socialization practices associated with dimensions of competence in pre-school boys and girls. Child Development 38, 291-327.

Barnett, R. C., \& Baruch, G. K. (1978). The competent woman. New York: Wiley \& Sons.

Biklen, S. K., \& Brannigan, M. B. (Eds.). (1980). Woman and educational leadership. Massachusetts: D. C. Heath. Biller, H. B. (1971). Father, child and sex role. Massachusetts: D. C. Heath.

Biller, H. B. (1974). Father power. New York: McKay. Borg, W. R., \& Gall, M. D. (1983). Educational Research (4th ed.). New York: Longman.

Boverman, I. K. (1972). Sex-role stereotypes: a current appraisal. Journal of Social Issues $28,59-78$.

Bradley, R. H. (1985). Fathers and the school age child. In S. M. Hanson \& F. W. Bozett (Eds.), Dimensions of fatherhood, pp. 141-169. Beverly Hills: Sage Publications.

Cartwright, L. K. (1970). Women in medical school. Dissertation Abstracts International.

Cath, S. H., \& Gurwitt, A. R., \& Ross, J. M. (Eds.). (1982). Father and child. Boston: Littie, Brown.

Collins, G. (1983, June 13). Redefining the role of fathers. New York Times, p. 20. 
Coopersmith, S. (1967). The antecedents of self-esteem. San Francisco: W. H. Freeman.

Constantini, E., \& Craik, K. H. (1982). Women as politicians: the social background, personality, and political careers of female party leaders. Journal of Social Issues, 28, 217-236.

Cummings, N. P. (1979). Women in higher education administration. In M. C. Berry (Ed.), Women in higher education, pp. 63-69. Washington, D.C.: The National Association for Women Deans.

Diamond H. (1978-79, Winter). Competency, confidence, courage: fundamental requirements for success. Educational Horizons, pp. 97-101.

Di Bella, C. M. (1979). System constraints on prospective women administrators. (Report No. EA 011 720). San Francisco: American Educational Research Association. (ERIC Document Reproduction Service No. ED. 172346 ).

Dickerson, K. G. (1978). Freshman university women receive inconsistent expectation messages from parents. (Report No. CG 014 272). (ERIC Document Reproduction Service No. ED. 184 032).

Dickerson, K. G., \& HinkTe, D. E. (1978). Expected to achieve - but not too much; conflicting expectations for entering college freshman women. The College Student Journal Monograph 12 (4, Part 2). Douvan, E. (1963). Employment and the adolescent. In F. I. Nye \& L. W. Hoffman (Eds.), The employed mother in America. Chicago: Rand McNally.

Ellison, C. W., \& Fireston, I. J. (1974). Development of interpersonal 
trust as a function of target status and target style. Journal of Personality and Social Psychology 29(5).

Erikson, E. H. (1980). Identity and the life cycle. New York: W. W. Norton.

Feldman, S. S., Nasch, S. C., \& Aschenbrenner, B. G. (1983). Antecedents of fathering. Child Development 54, pp. 1628-1636. Fields, S. (1983). Like father, like daughter. Boston: Little, Brown. Fishel, A., \& Pottker, J. (1979). Performance of women principals: a review of behavioral and attitudinal studies in M. C. Berry (Ed.), Women in higher education, pp. 24-31. Washington, D. C.: The National Association for Women Deans.

Fitzgerald, L. E. (1979). Our dwindling national resources: women school administrators. In M. C. Berry (Ed.), Women in higher education, $p p \cdot 32-46$. Washington, D. C.: The National Association for Women Deans.

Friedman, S. (1983, August). Fathers and daughters. Cosmopolitan, p. $166(4)$.

Gilligan, C. (1982). In a different voice. Cambridge: Harvard University Press.

Gordon, R. L. (1980). Interviewing strategy techniques and tactics. (3rd ed.). Homewood, IL: The Dorsey Pess. Gordon, S., \& Ball, P. G. (1979). Survival dynamics for women in educational administration. In M. C. Berry (Ed.), Women in higher education, pp. 125-129. Washington, D. C.: The National Association for Women Deans. 
Gough, H. G., Ph.D. (1965). The adjective check list. Palo Alto, California: Consulting Psycholgists Press.

Green, M. (1976). Goodbye father. London: Routledge \& Paul. Hamilton, M. L. (1971). Father's influence on children. Chicago: Nelson-Hall

Hammer, S. (1982). Passionate attachements. New York: Rawson Associates.

Harder, M., \& Waldo, K. (1983, Fal1). Women as educational leaders: the theories behind the facts. Action in teacher education, pp. $35-40$.

Havighurst, R. (1972). (3rd Ed.) Development tasks and education.

New York: David McKay.

Helson, R. (1967). Personality characteristics and developmental

history of creative college women. Genetic Psychology Monographs 76- $(35), 214-233$.

Helson, R. (1971). Women mathematicians and the creative personality. Journal of Consulting and Clinical Psychology 36, No. 2. pp. 210-220. Hennig, M., \& Jardin, A. (1976). The managerial woman. New York:

Pocket Books.

Hoffman, M. L. (1970). Moral development. In P. H. Mussen (Ed.), Carmichael's manual of child psychology, (Vol. 2). New York: Wiley. Horner, M. S. (1975). Toward an understanding of achievement - related conflicts in women. In M. Mednick, S. Tangri, \& L. W. Hoffman (Ed.), Women and achievement; social and motivational. New York: Hemisphere Publishing Corp. 
Horner, M. (1977). And Jill came tumbling after: sexism in American education. New York: Dell Publishing Company. Hunt, B., \& Hunt, M. (1980, May) Your father/yourself. Ladies Home Journal, p. 101 (8).

Jones, L. C. (1985). Father-infant relationships in the first year of life. In S. M. Hanson \& F. W. Bozett (Eds.), Dimensions of fatherhood, pp.91-114. Beverly Hills: Sage Publications. Kahn, D. G. (1981). Fathers as mentors to daughters. (Report No. CG 016 369). Cambridge, MA: Radcliffe Institute, Radcliff College. (ERIC Document Reproduction Service No. ED 223-960). Keller, H. R. (1980). Working and parenting: the male and father role. In S. K. Biklen \& M. B. Brannigan (Eds.). Women and educational leadership (pp. 197-208). Massachusetts: D. C. Heath. Kotelchuck, M. (1972). The nature of the child's tie to his father. Unpublished doctoral dissertation, Harvard University, Mass. Kurcoff, C. (1983, August 24). My father, myself. Washington Post, p. 81.

Lamb, M. E. (1976). The role of the father in child development. New York: Wiley and Sons. Lamb, M. E. (1981). The role of the father in child development. New York: Wiley and Sons. Lever,, J. (1976). Sex differences in the games children play. Social Problems, (23), 478-487. Levinson, D. J. (1978). The season of a man's life. New York: Ballantine. 
Lewis, M., \& Weinraub, M. (1976). The father's role in the child's social network. In M. E. Lamb (Ed.), The role of the father in child development (pp. 259-287). New York: Wiley \& Sons

Lynn, D. B., (1974) The father. Monterey: Brooks/Cole. Mackay, K., (1983, Apri1 6). How fathers influence daughters. Los Angeles Times, Sec. V., p. 1.

Mauch, J. E., \& Birch, J.W. (1983). Guide to the successful thes is and dissertation. New York: Marcel Dekker, Inc.

Metzger, C. (1985). Helping women prepare for principalships. Phi Delta Kappan, p. 292.

Middleton-Moz, J., \& Dwinel1, L. (1986). After the tears: Pompano Beach, FL.Health Communications, Inc.

Molyneau, D., and Lane, V. (1981). Effective interviewing techniques; an analyses. Boston: Allyn \& Bacon.

Musser, J. M., \& Fleck, J.R. (1983, Winter). The relationship of paternal acceptance and control to college females personality adjustment. Adolescence, pp. 907-915.

Newman, B. M., \& Newman, P. R. (1984). Development through life; a psychosocial approach. Illinois: Dorsey Press.

Noe1, P. (1983, December). The men behind their success. Ebony, p. $124(4)$.

Osofsky, J. D. (1972). Relationships between fathers' reported and observed behaviors with daughters. (Report No. PS 006 144). Honolulu, Hawaii: American Psychological Association. (ERIC Document Reproduction Service No. Ed 069 415). 
Parsons, T. (1955). Family structure and the socialization of the child. In T. Parsons \& R. F. Bales (Eds.), Family, socialization and interaction process. I11 inois: Free Press.

Radin, B. A. (1980, March-April). Leadership training for women in state and local government). Public Personnel Management, pp. 53-60.

Rivers, C., \& Barnett, R., \& Baruch, G. (1979). Beyond sugar and spice. New York: Ballantine Books

Romano, D. L. (1980, September). Sexual confidence. McCall's, p. $113(4)$.

Rosen, J. L. (1977). Early predictors of leadership in women educators; personality and career over two decades. (Report No. PS 009 676). New York: Bank Street College of College Education. (ERIC Document Reproduction Service No. 147 024).

Rossi, B. H. \& Griffiths, D. (1984). Using the case study research strategy: considerations and suggestions. Unpublished manuscript, New York University.

Saunders, M. P. (1985, August). Fathers and daughters. Essence, p. $85(3)$.

Schetlin, E. M. (1979). Wonderland and looking-glass: women in administration. In M. C. Berry (Ed.), Women in higher education, pp. 47-52. Washington, D. C.: The National Association for Women Deans. Sheehy, G. (1974). Passages. New York: Bantam Books. Shakeshaft, C. (1987). Women in educational administration. Beverly Hills: Sage Publications. Stake, R. (1978). The case study method in social inquiry. 
Educational Researcher, $\underline{7}(2), 5-8$.

Stein, E. V. (1977). Fathering: fact or fable? Nashville: Abingdon.

Stevens, J. H., \& Mathews, M. (Eds.). (1978). Mother/child,

father/child relationships. Washington, D. C.: National Association for the Education of Young Children.

Stewart, C. (1974). Interviewing principals and practices. Dubuque, Iowa: W. C. Brown.

Tibbetts, S. L. (1979). Sex-role stereotyping: why women discriminate against themselves. In M. C. Berry (Ed.), Women in higher education, pp. 118-124. Washington, D. C.: The National Association for Women Deans.

Tibbetts, S. L. (1979). Why don't women aspire to leadership positions in education? In M. C. Berry (Ed.), Women in higher education, pp. 1-11. Washington, D. C.: The National Association for Women Deans. Truett, C. (1979). Women in educational administration: is there a basic role conflict? (Report No. EA 011880 ). Bloomington, Indiana: Conference on Women and Work. (ERIC Document Reproduction Service No. $172400)$.

Turner, J. S., \& Helms, B. S. (1979). Contemporary adulthood. Philadelphia: W. B. Saunders. - (1984, March 19). 10 forces reshaping America. U.S. News and World Report, pp. 40-52.

Van Mier, E. J. (1975, Summer). Sexual discrimination in school administration opportunities. Journal of the National Association of Deans, $38,163-167$. 
Webster's Third New International Dictionary. (1976). p. 828.

Weinraub, M., (1978). Father: the myth of the second-class parent. in

J. H. Stevens and M. Mathews (Eds.). Mother/child; father/child

(pp. 109-133). Washington, D. C.: National Association for the

Education of Young Children.

Woolfolk, W. (1982). Daddy's little girl. New Jersey: Prentice-Hall, Inc.

Woo, L. C. (1985, December) Women administrators: profile of success. Phi Delta Kappan. p. 285-289. 


\section{Appendix A}

San Diego Council of Administrative Women in Education Newsletter, Advance, April 1986 


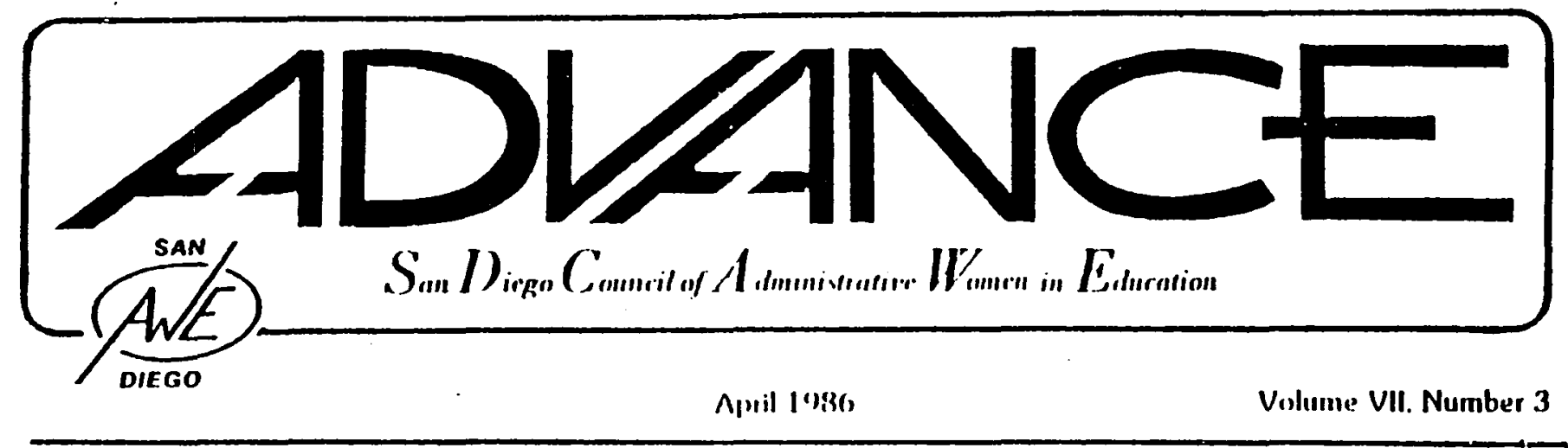

\section{Assistance Needed With Dissertation}

Marilyn Skordas, a docloral candidale at the Unluersily of San Diegn and a member of SDCAWE. is currenlly worktng on her dissertallon entlled "The linpacl of the Fallier/Daughter Relallon. ship on Women in Educatlonal Admin. istralive leadership Posillons."

Research sludies indicate that the major elensent in the llues of successful womien In liee lields of medicline, gov. erimnent, business, and math was the Influence and impact the lallies had upon thelr successes and aclilevernents. This dissertation will explore and examine how and how inizch falliers related to and behaved will, their danghilers who now liold an adininistralive posillon In the lield of education, all ocrupation not yel researched. The linlonitlon of this rase sludy is lo contilumic lo and enhance the Ilteralure regniding women in educallonal administrative positlous by bring. ling psycholougle al and sociologic al llireory In line with pursomal expretlences of the laller/daughitor rolationshilp. as virwed in Ihree major phases of development: middle childlinod, adolescence, and early adultionis.

This dissertalion is a case study which will Involue the filf erviewing of 12 women whos currently luold an administratlue posillon of mincipal or above at the plemenlary. siecomilary, or dislrict ollice level Each silected subject will be re quested to commit in two. three-hour inlervlew sessinns: dales, llmes and lu callons to be deternilined by the selecled sublect. These interviews will take place during the summer montlis of July and August. Each sillyect will be requested to sign an lnformed consent ossuring sub. Jects of confldenllality and anonymily.

The SDCAWr: members who lall into line pilnclpal or above calegory are rerguested to lill out the enclosed Insert and relurn If In the allached, sell-ad. dressed, slamiped envelope as soon as possible.

II you have questlons regarding your matleipallon. please call Marllyn Skordas at home at 292.7499 (evellings). 
Appendix B

Letter of Appreciation to Pre-selected Candidates 
Appendix B

July 30,1986

Dear

I wanted to thank you again for your responses and your time spent filling out the Dissertation Interview Information Sheet for my dissertation, "The Impact of the Father/Daughter Relationship on Women in Educational Administrative Leadership Positions."

I also wanted to share with you that as a result of established criteria for this dissertation, you were not selected to be interviewed.

I look forward to sharing the information with you as well as with other members of the San Diego Council of Administrative Women in Education.

Thank you very much for your interest and support.

Sincerely yours, 
Appendix C

University of San Diego Consent Form 


\author{
Appendix C \\ University of San Diego \\ Consent Form
}

Research: The Impact of the Father/Daughter Relationship on Women in Educational Administrative Leadership Positions

Researcher: Marilyn M. Skordas, M.Ed.

Purpose: The purpose of this research is to contribute to the 1 iterature regarding women in educational administrative positions by bringing

psychological and sociological theory in line with personal experiences of the father/duaghter relationship as viewed in three major phases of development: middle childhood, adolescence, and early adulthood.

Procedures and Protections: There are no foreseen risks to this research. Your participation in this research is strictly on a voluntary basis with the understanding that you may withdraw at any time.

You will be interviewed by this researcher during the Summer and/or Fall of 1986. The interviews will be tape recorded and coded for purposes of confidentiality and anonymity. Your name will not be used unless you waive this right. Coded, transcribed interviews and their interpretations will then be reviewed by two expert consultants selected by this researcher.

It is expected that your participation will be limited to two three-hour taped interview sessions between July, 1986 and October, 1986. The date, time, and location of each interview will be based on what is most comfortable and accommodating to meeting your needs.

It is hoped that through your participation in this study that you gain an insight and appreciation of the inner dynamics of your relationship with your father and the impact of that relationship on your personal and professional life.

You may ask questions about the procedure, and have those questions answered, before you sign this form.

You and this researcher have no agreement, written or veral, other than what is expressed on this form.

Consent: I, the undersigned, understand the above explanations and, on that basis, I give consent to my voluntary participation in this research.

$\overline{\text { Participant }} \overline{\text { Date }}$

Location

Researcher

Date 
Appendix D

Dissertation Interview Information Sheet 
Appendix D

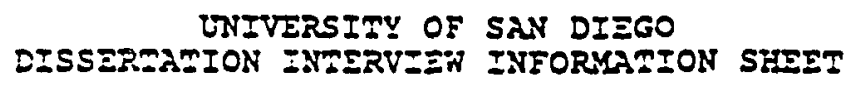

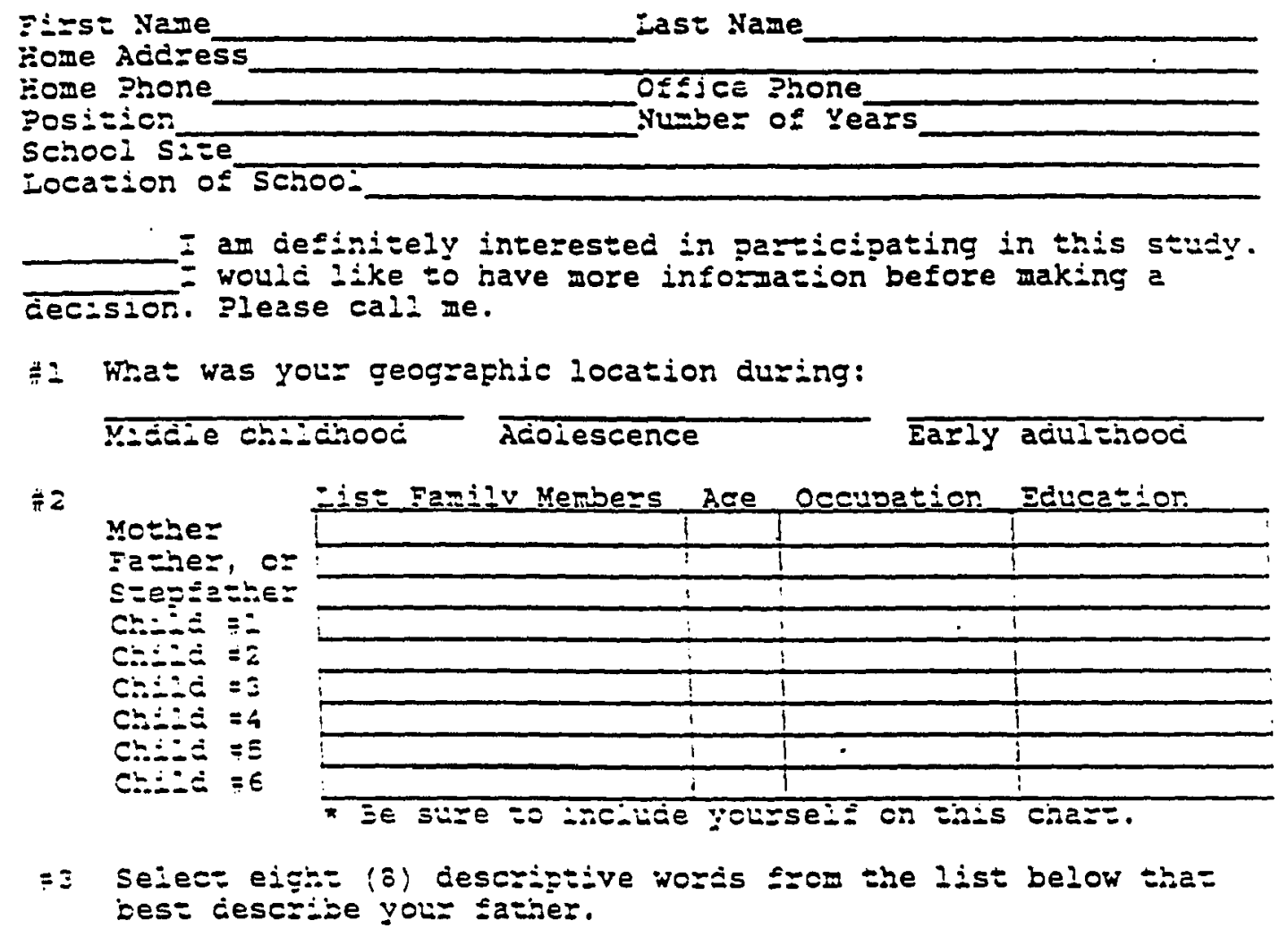

If Seject eich: (E) descziztive words frou the list below shat best cescitide your moiher.

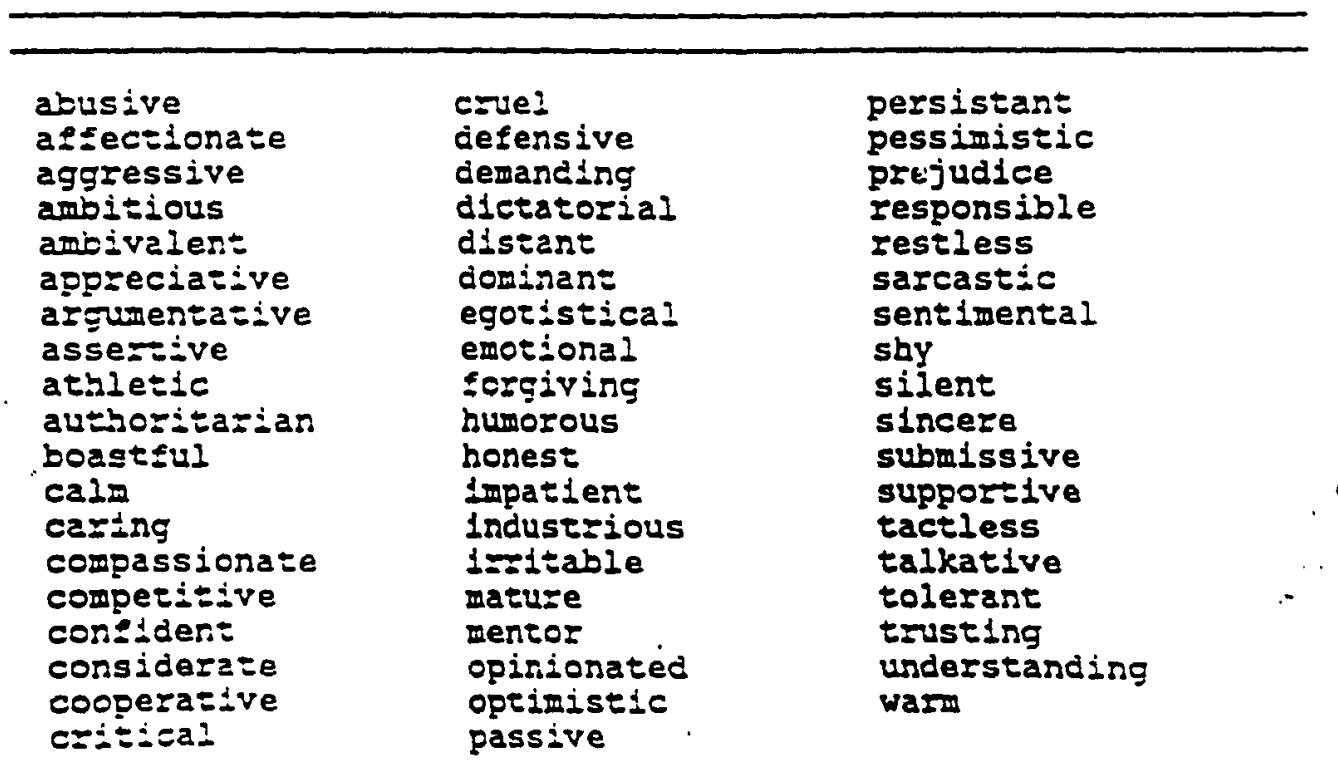


Appendix E

Interview Guide

Reproduced with permission of the copyright owner. Further reproduction prohibited without permission. 


\section{Appendix E \\ Middle Childhood Years}

A. If your father were talking to his best friend about you during this life stage between the ages of 8 to 12, what would he have said about you?

B. If you were talking to a friend at this time in your life, how would you have described your father? Or what would you have said about him?

\section{DEVELOPMENTAL TASKS QUESTIONS}

\section{Social Cooperation}

1. What do you remember about your friends at this age?

2. How did you feel about your friends?

3. Was your father aware of your friends?

4. Did your father have any influence or give you any advice regarding your relationships with your friends?

\section{Self Evaluation}

1. How did you feel about yourself at this time in your life?

2. Was your father aware of how you felt?

3. Did anything he said contribute to the way you felt about yourself?

\section{Skill Learning}

1. How did you feel about school at this age?

2. How did you feel about yourself in school?

3. Did your father help you in any way with your schooling at this time?

4. What importance, if any, did your father place on school? Homework?

5. What kinds of non-academic skills or talents did you learn at home? Who helped you learn these skills?

Team Play 
1. What kind of extra curricular activities did you participate in?

2. Did your father actively participate or play a role in or support you in these activities?

C. If you had to summarize the major influence your father had at this point on your life, what would you have said?

D. What, if anything would you have liked more of from your father or what could your father have done during your middle childhood years to better meet your needs?

\section{Early Adolescence}

A. If your father were talking to his best friend about you during this life stage between the ages of 13 to 17 , what would he have said about you?

B. If you were talking to a friend at this time in your life, how would you have described your father? Or what would you have said about him?

DEVELOPMENTAL TASKS

QUESTIONS

Physical Maturation

1. During early adolescence, one goes through many changes; how did you feel about this?

2. Was your father aware of those changes?

3. Did your father notice or make comments about your physical appearance?

4. Did your father have any influence on how you felt about your physical changes?

\section{Formal Operations}

1. Was there any time in your family life when you talked about what was going on in the environment outside the home?

2. What importance, if any, did your father place on school? Community? Nation?

4. Did your father have any influence on how you thought or felt about the world and the events going on in the world during your early adolescence? 
5. What rules, if any, were you asked to follow?

6. How did you feel about those rules?

7. What part did your father play in making these rules and/or enforcing them?

\section{Emotional Development}

1. As you reflect back on what your adolescent life was like for you, what particular areas were of concern? What areas of your life made your happy? Sad?

2. What part did your father play in your life when you were going through your development during early adolescence?

3. Did you choose someone to model?

4. Did your father see anyone or admire in your life or in the world who exhibited behaviors that he thought you should model?

5. Would you consider your father a model for you?

Membership in the Peer Group

1. How would you describe your peer group?

2. Did you have close friendships with girls? Boys?

3. How would you consider your place in your group of friends?

4. Would you at this time, in early adolescence, consider yourself to be a leader?

5. Did you hold any leadership positions in school? Social?

6. Did your father help or advise you in any way in making the decision to obtain a leadership position?

7. Did he relate any of his leadership experiences to you?

\section{Heterosexual Relations}

1. At this age, how would you describe your relationships with:

$$
\text { -- boys? girls? }
$$

-- adults? teachers?

-- authority figures?

2. What was your father's attitude toward:

$$
\text { -- boys? girls? }
$$


-- adults? teachers?
-- authority figures?

C. If you had to summarize the major influence your father had at this point on your life, what would you have said?

D. What, if anything would you have liked more of from your father or what could your father have done during your early adolescence to better meet your needs?

\section{Later Adolescence}

A. If your father were talking to his best friend about you during this life stage between the ages of 18 to 22, what would he have said about you?

B. If you were talking to a friend at this time in your life, how would you have described your father? Or what would you have said about him?

DEVELOPMENTAL TASKS

QUESTIONS

Autonomy from Parents

As you reflect on being a female adolescent

1. Were there any ways you felt dependent on your parents at this time?

2. How did you start to show your independence?

3. How did your father, if he did, encourage your dependence or independence?

\section{Sex Role Identity}

1. How did you feel about being female? Becoming a woman?

2. Who did you more closely identify with - in your family? Outside your family?

3. How did your father feel about you being female?

Internalized Morality

1. During adolescence, how did you make decisions?

2. Did your father have any input to your decision making process? 
3. How did you feel at this time about the standards that were set for you?

\section{Career Choice}

1. What kinds of things did you do in later adolescence to help you in making a career choice?

2. When did it become clear to you that you wanted to enter the teaching profession?

3. What kind of input or influence did your father have, if any, on this decision?

C. If you had to summarize the major influence your father had at this point on your life, what would you have said?

D. What, if anything would you have liked more of from your father or what could your father have done during your later adolescent years to better meet your needs?

\section{Early Adulthood}

A. If your father were talking to his best friend about you during this life stage between the ages of 23 to 34 , what would he have said about you?

B. If you were talking to a friend at this time in your life, how would you have described your father? Or what would you have said about him?

DEVELOPMENTAL TASKS

QUESTIONS

Marriage

1. During this period of time, did you make a decision about whether marriage would be a part of your life goal?

2. In perceiving or observing your parents' marriage, how did you feel about marriage and when or who you would marry?

3. Did your father have any influence on whether marriage would be a part of your life?

4. Do you feel you married a man who has qualities of your father? Childbearing

1. How did you feel at this time about whether bearing children would be a part of your life goal? 
2. In observing your parents' marriage and your upbringing, did that affect whether you wanted children or not?

Work

1. How did you select your first work environment?

2. Did your father have any influence on the way you adapted to your work environment? Organizational skill?

3. Who do you feel you work with or relate to best in a work environment -- men or women?

4. Do you feel your relationship with your father helped or hindered this?

\section{Lifestyle}

1. What were your future life goals at this time?

2. Did your father influence the way you live. today?

C. If you had to summarize the major influence your father had at this point on your life, what would you have said?

D. What, if anything would you have liked more of from your father or what could your father have done during your early adulthood years to better meet your needs?

The Last Question:

If you had a good friend who had just become the father of a brand new baby girl ... what message would you want to share with that father? 